\title{
711/842. Siglo y medio de la cultura material de la España cristiana desde la invasión. Musulmanes y cristianos determinantes de una mistificación "históricocultural" que no cesa
}

\author{
Isidro G. BANGO TORVISO \\ Universidad Autónoma de Madrid \\ isidro.bango@uam.es
}

Dar una respuesta con una cierta coherencia al título de esta ponencia me parece difícil. Esta dificultad no se debe tanto, aunque también, a los problemas lógicos de datación y clasificación, como a un mal uso de la nomenclatura de la historia de los estilos y de su exacto conocimiento. Algunos investigadores siguen asumiendo una terminología estilística del siglo XIX, cosa que es grave, pero todavía lo es más el que no comprendan términos que tan solo tienen una condición de referente histórico/ cronológico para un contenido estilístico/artístico. Para muchos, lo étnico/religioso/político es una manera muy cómoda para calificar una obra de arte. Sin duda lo es, si tan solo pretendemos situarla en el tiempo y en el espacio, pero debemos ser conscientes de cuál es el origen de la forma y de la técnica. Por ejemplo, las grandes obras artísticas del siglo IV realizadas para uso de los cristianos podemos llamarlas paleocristianas en el sentido de que son manifestaciones antiguas de los cristianos, pero desde el punto de vista del estilo, de la forma y de la técnica siguen siendo arte romano. Esta tendencia a utilizar confusamente la terminología suele pretender, consciente o inconscientemente, la configuración de un cierto "imperialismo" ideológico. Es la manera de magnificar una religión, una etnia, o simplemente un grupo de poder. Expresiones como paleocristiano y la cada vez más utilizada paleoislámico se entienden perfectamente desde el punto de vista etimológico: son las obras más antiguas de cristianos o de musulmanes. Pero lo que no podemos hacer, es no calificarlas desde el punto de vista estilístico/artístico como obras romanas de la cronología y área geográfica a las que pertenecen. No creo que haya nadie con conocimientos de historia del arte y sin prejuicios ideológicos que pueda dudar de la romanidad de las basílicas constantinianas, de la mezquita de Damasco o del mosaico de Khirbat al-Mafjar (Jerusalén, Museo Arqueológico).

Centrémonos ahora en la historiografía sobre el marco artístico hispano de los siglos V al VIII. Nos encontramos como todavía hay investigadores que califican ciertas obras hispanas de este período como propias del arte bizantino, cuando los 
especialistas en arte bizantino no definen este período como tal ${ }^{1}$. Desde el excelente estudio presentado por Palol en Spoleto, pienso que la denominación y contenido del arte en la España gobernada por la monarquía goda había quedado perfectamente clarificada o, al menos, con criterios para precisar el significado de la nomenclatura empleada ${ }^{2}$. Sin embargo resulta desalentador ver como durante los últimos veinte años muchos investigadores califican de visigodas o de germánicas obras que evidentemente no lo son. Todavía recuerdo el texto de Camps en el que se nos trasmitía una visión de la cultura material hispana donde lo godo se iba detectando según el dominio del pueblo godo se iba afianzando de Norte a $\mathrm{Sur}^{3}$. Por esta razón es necesario ser lo más preciso posible a la hora de emplear el término arte visigodo, no conviene utilizarlo salvo que se refiera exactamente a él ${ }^{4}$. Y hablando de confusión, parece increíble que se siga manteniendo el adjetivo germánico para calificar determinadas obras tardorromanas o altomedievales, confirmando con ello catalogaciones absurdas. Obsérvese a este respecto la identificación que Lecanda realiza para las iglesias burgalesas de Mijangos: "Que esos fundamentos culturales permiten la incor-

1 Por no entrar en las prolijas disquisiciones que este planteamiento requeriría, nos bastará aquí reproducir la interpretación que C. Mango ofrece para la arquitectura: "Existe, por tanto, razón suficiente para trazar una línea divisoria en el siglo VII y aplicar el término Paleocristiana (o Tardorromana) a la arquitectura que antecede tal línea, y Bizantina a la que se produce después". C. MANGO, Arquitectura bizantina, Madrid, 1975 , p. 9.

2 Algunas expresiones concretas no fueron del todo precisas, pero al menos permitieron acabar con el mal uso de conceptos como romanismo y germanismo (P. DE PALOL I SALELLAS, "Esencia del arte hispánico de época visigoda: romanismo y germanismo", I goti in Occidente. Problemi. Settimane di Studio del Centro Italiano de Studi sull'Alto Medioevo (Spoleto, 29 marzo-5 aprile 1955), vol. III, Spoleto, 1956, pp. 65-126).

3 E. CAMPS CAZORLA, "El arte hispanogodo", Historia de España, dir. R. Menéndez Pidal, t. III, Madrid, 1963, pp. 497-498.

4 Hace unos años Achim Arbeitter titulaba con absoluta precisión terminológica el contenido de un estudio suyo: "inventario monumental hispanovisigodo". Al principio centra el tema que va a tratar: "monumentos arquitectónicos y escultóricos que tradicionalmente se asignaban al reino visigodo". En nota explica lo que quiere decir con visigodo: "empleo el término visigodo no con acepción étnica, sino para denominar un marco cultural de toda la comunidad hispánica en determinada época". Es evidente que este autor es consciente de lo que significa hispanogodo y visigodo, incluso con buena voluntad acabamos de ver que lo explicita. No obstante a lo largo de todo el estudio repite una y otra vez el calificativo visigodo, propiciando desde mi punto de vista, una enfatización no solo innecesaria sino que induce a una confusa ambigüedad (A. ARBEITER, "Alegato por la riqueza del inventario monumental hispanovisigodo", L. CABALLERO y P. MATEOS (eds.), Visigodos y Omeyas. Un debate entre la Antigüedad Tardía y la Alta Edad Media, Madrid, 2000, pp. 249-263, especialmente. p. 249 y n. 3). De la ambigua interpretación de estos términos con la consiguiente distorsión involuntaria del significado y contenido de este arte véase el caso de Caballero, uno de nuestros más experimentados investigadores sobre este período: refiriéndose a la arquitectura le es indiferente que se utilice la expresión visigoda o hispanogoda (L. CABALLERO ZOREDA, "La arquitectura denominada de época visigoda ¿Es realmente tardorromana o prerrománica”, L. CABALLERO Y P. MATEOS (eds.), Visigodos y Omeyas. Un debate entre la Antigüedad Tardia y la Alta Edad Media, Madrid, 2000, p. 207). Desde el estudio de otras materias, lengua y literatura, sucede la misma confusa utilización de la nomenclatura y su verdadero significado. He elegido un texto de Juan Gil para ilustrar esto, especialmente por la enorme autoridad y competencia que este investigador representa. Refiriéndose a Albaro (800? \pm 861$)$ afirma: "En lo fundamental Albaro continúa siendo un visigodo”. Y a continuación concluye: “乌habremos de llamar godos a los mozárabes? Evidentemente no, porque no lo fueron en modo alguno" (J. GIL, "Aproximación a la literatura latina de los mozárabes", Actas del I Congreso Nacional de Cultura Mozárabe -Historia, Arte, Literatura y Música, Córdoba, 1996, p. 93). No dudo de que Gil no se refiere exactamente a los godos aquí como un grupo étnico concreto, sino a la totalidad de la población de la España gobernada por los godos. Parece que es un detalle sin importancia pero, al menos, puede inducir a la confusión. 
poración de elementos claramente germánicos, como la decoración a base de círculos tangentes, concéntricos y secantes, hecho que los dota de personalidad artística y que anuncia, claramente, quienes son los comitentes" ${ }^{\circ}$. ¿Se pueden denominar germánicos estos motivos decorativos? ¿Es posible que estos motivos puedan identificar una etnia durante la Alta Edad Media?

Como lo trataré más adelante, no me detendré ahora en una nueva polémica estilística, pero si me gustaría dejar clara mi opinión sobre el particular desde el principio. Me refiero a la nueva disyuntiva planteada por Caballero: la arquitectura de época visigoda es tardorromana o prerrománica ${ }^{6}$. Si, tal como explicaré, llamar prerrománico al arte del reino astur es un grave error, hacerlo con el arte hispanogodo es todavía menos adecuado. A continuación desarrollaré mi trabajo en dos partes bien diferenciadas: 1. Introducción; 2 . Arte de la monarquía astur.

\section{INTRODUCCIÓN}

Como el tema es saber si después del 711 se produce una ruptura artística con el pasado, nos conviene precisar algunos aspectos sobre esta cultura del pasado (hispanogoda) y sobre lo que ocurrirá entre los musulmanes y los cristianos sometidos a su autoridad. Con este apartado introductorio solo pretendo señalar algunos conceptos de tipo general.

\section{1. ARTE HISPANOGODO}

Con este nombre se denomina el arte que se realiza en España bajo la monarquía goda. En cuanto a contenido y significado quiero dejar claro que se trata de un arte tardorromano o, como mínimo, según denominación propuesta de Kitzinger, subantiguo $^{7}$. Aunque en los últimos años se ha progresado muchísimo en su conocimiento, seguimos manteniendo grandes interrogantes sin resolver o aceptando los tópicos a los que ya nos hemos referido. No se tiene en cuenta la diversidad del arte romano que tiene también su continuación en este período. A su vez, y especialmente en los motivos figurativos en general, existe una amplia difusión por todo el imperio que hace que, siglos después, todavía sigan siendo modelos a imitar sin necesidad de acudir a fuentes lejanas para justificar su presencia en España. Me refiero a esos temas, geométricos o vegetales, que en el siglo VIII o IX se quieren hacer viajar desde miles de kilómetros de distancia, cuando lo lógico es que su origen esté en el mismo paisaje monumental hispano.

5 J. Á. LECANDA, "Mijangos: La aportación de la epigrafía y el análisis arqueológico al conocimiento de la transición a la Alta Edad Media en Castilla", L. CABALLERO Y P. MATEOS (eds.), Visigodos y Omeyas. Un debate entre la Antigüedad Tardia y la Alta Edad Media, Madrid, 2000, p. 203.

6 L. CABALLERO ZOREDA, op. cit., 2000, p. 207.

7 Con esta expresión el historiador admite que no estamos ante un arte tardorromano de primera época, pero que sin duda el arte de esta época no merece el adjetivo de medieval, sino que todavía debe considerarse antiguo (E. KITZINGER, Early Medieval Art, Londres, 1983 (primera edición, 1940), especialmente el capítulo "The Late Antique and Early Christian Period", pp. 11-45). 


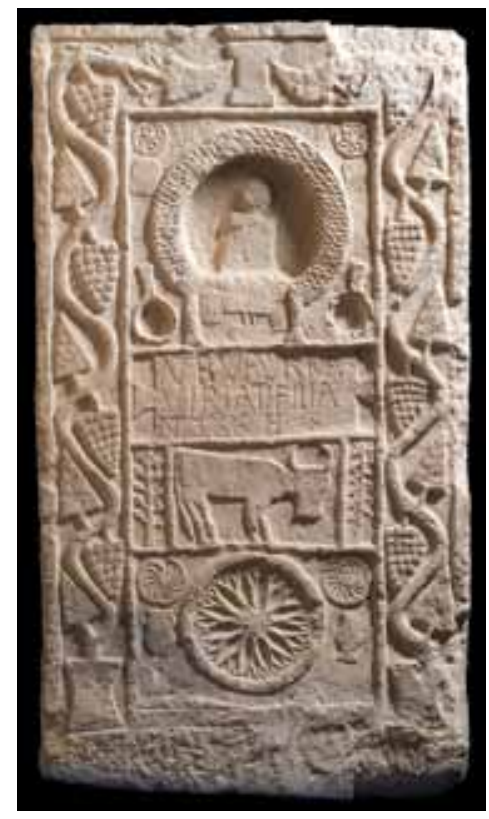

Fig. 1

Sobre la escultura, monumental o no, detectamos las dos tendencias claramente definidas por los historiadores clásicos del arte romano. Una corresponde al sermo rusticus, o a una variante más popular del mismo claramente enraizada en la tradición prerromana. La célebre estela de Ania Buturra (fig. 1$)^{8}$ nos suministra un buen ejemplo de la técnica y de un amplio repertorio iconográfico. Su talla a bisel nos ilustra de una técnica de origen antiquísimo y de una amplísima pervivencia. Huelgan idénticos comentarios sobre los temas reproducidos: tallo sinuoso con racimos y hojas alanceoladas en los senos, trisqueles, rosetas enfiladas en círculos, estilizados vegetales, etc. $\mathrm{El}$ arco de herradura que contemplamos merece un comentario especial, pues nos permite conocer el verdadero sentido de este elemento. Aquí, al tratarse de una función meramente ornamental, su autor ha podido desarrollar una herradura con un peralte muy acusado, pues carece de efecto dinámico que pudiera afectar a su estabilidad. La arquitectura tardorromana contempló el empleo del arco de herradura considerando que el efecto estético radicaba en la altura de este peralte, pero sus constructores se veían obligados a limitarla en función de esfuerzos y cargas que el arco desempeñase. Veamos otra obra: el relieve con inscripción alusiva al credo, conservado en el Museo de los Concilios de Toledo (fig. 2a). Su cadeneta de ochos o simplemente círculos, así como los vegetales estilizados nos indican que estamos ante el mismo tipo de arte del que hablamos. Los capiteles de la iglesia de San Millán de la Cogolla, realizados después de la destrucción del templo por la campaña de Almanzor, son un testimonio de la pervivencia del mismo recurso plástico (fig. 2b).

8 Conservada en el Museo de Navarra procedente de la ermita de San Sebastián de Gastiáin (Museo de Navarra. Textos e introducción Ma Ángeles Mezquíriz, Pamplona, 1998, p. 40). 


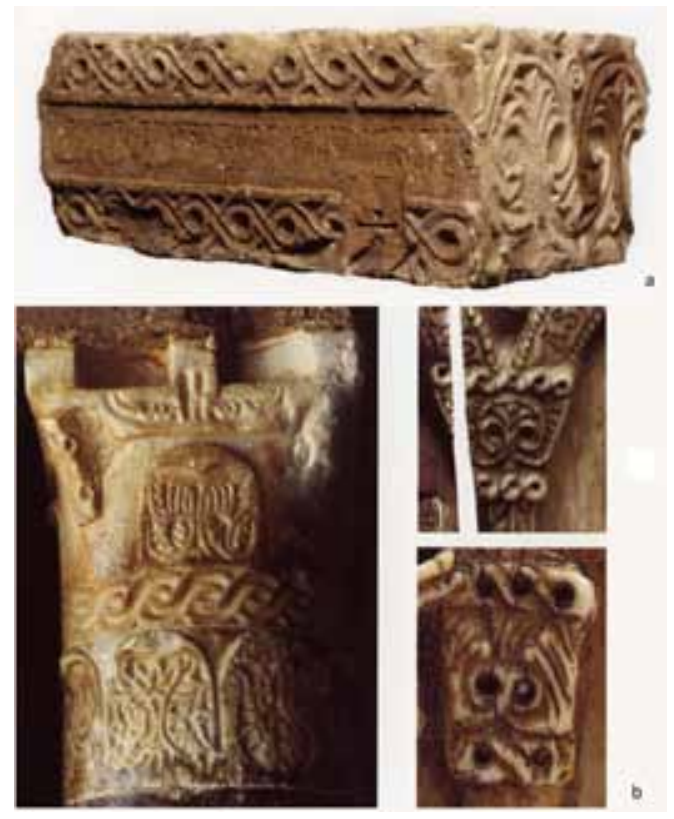

Fig. 2

También existen otras tendencias, como la de intención naturalista, aunque de una difusión más limitada. Podemos comprobarlo en un fragmento de cancel, conservado en el Museo de Santa Cruz (Toledo), donde contemplamos la imagen del toro emblemático del evangelista Lucas (fig. 3a) ${ }^{9}$. La rareza de la pieza, según algunos, conduce a realizar propuestas de catalogación ciertamente extravagantes: "relieve de influencia italiana con el Evangelista San Lucas" ${ }^{10}$. Por desgracia no conservamos muchos ejemplos de esta forma de representar, pero debió ser abundantemente empleada tal como demuestra su mantenimiento en otro tipo de soporte: el mismo símbolo de Lucas de la Biblia Hispalense (fig. 3b) ${ }^{11}$.

\section{2. ARTE POSTHISPANOGODO}

Con este apartado no pretendo propiciar una nueva nomenclatura artística hispana, pero sí corregir una interpretación sesgada de las formas y hacer un breve comentario con lo que sucede inmediatamente después de iniciarse la invasión. Dado lo que hemos hablado del empleo generalmente incorrecto del término arte godo, con el mismo criterio debemos censurar la expresión postgodo. Curiosamente esta ex-

9 Procede de las obras realizadas en el Miradero (Toledo). Su tamaño 36 x 367 x $20 \mathrm{~cm}$ (R. BARROSO y J. MORÍN DE PABLOS, El Toledo visigodo a través de su escultura monumental. Regia Sedes Toletana, vol. II, Toledo, 2007, n 47, p. 207.

10 S. CORTÉS HERNÁNDEZ y E. OCAÑA RODRÍGUEZ, "Relieve con representación del Evangelista San Lucas”, Hispania Gothorum. San Ildefonso y el reino Visigodo de Toledo, Toledo, 2007, p. 553.

11 Códice Vitr. 13 - 1, detalle del fol. 278r (Madrid, Biblioteca Nacional). Esta obra se suele datar hacia 900 . 


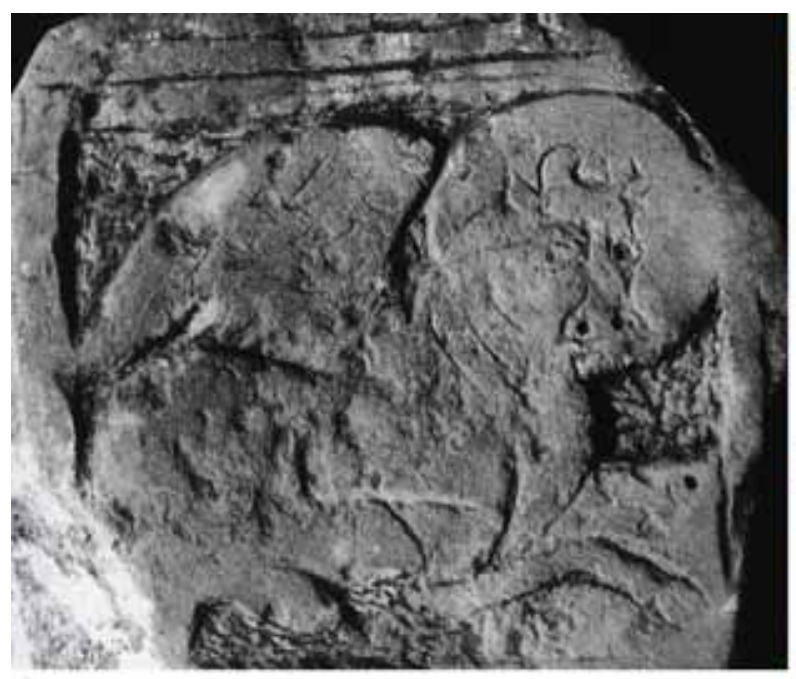

a

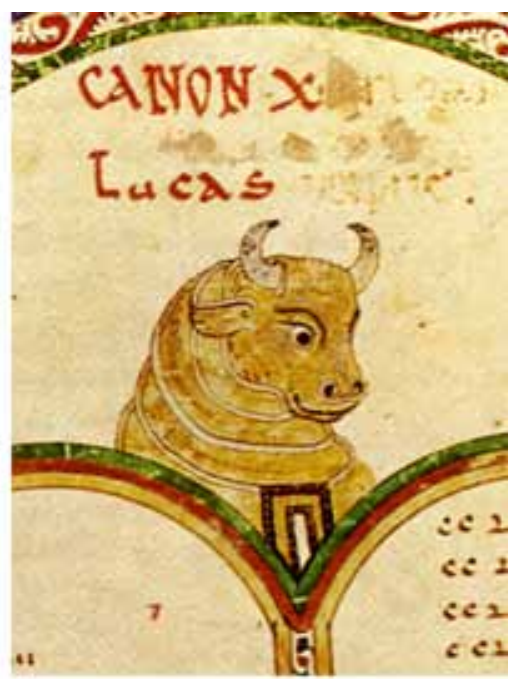

Fig. 3

presión solo se suele emplear para algunas formas artísticas de la órbita cristiana. Aunque parezca mentira, todavía existen investigadores a los que hay que recordar que el mundo de las formas no cambia radicalmente con una invasión. Este aspecto se acentúa aún más cuando se trata de los invasores musulmanes. El reducido número de estos en comparación con los invadidos les obligaba a valerse de la mano de obra local, con lo que esto suponía. Así pues, y siendo estrictos, existió inmediatamente después de la invasión una continuidad del arte hispanogodo, lo posthispanogodo si es que queremos citarlo con mayor precisión ${ }^{12}$. Pero esto no es el tema, pues es algo indiscutible, el problema es fijar durante cuánto tiempo pervivió. Sin entrar en el detalle del asunto me gustaría abordarlo en este apartado meramente introductorio, manteniendo una más que discutible diferenciación religiosa: posthispanogodo entre musulmanes y posthispanogodo entre cristianos.

1.2.1. Arte posthispanogodo ENTRE los Musulmanes. El proyecto de la MEZQUita de CÓRDOBA

Nadie cuestiona que con la mezquita de Córdoba estamos ante el proyecto monumental más paradigmático construido para los musulmanes en la España del siglo VIII. Su definición artística nos dará la clave para identificar el arte más importante y significativo entre los musulmanes. Sabemos que para la construcción de este edificio se compró entre los años 784-785 el solar necesario. Las obras, iniciadas en 785-786,

12 En un principio tenemos que dar la razón a Maravall cuando nos dice que la España de los musulmanes y la de los cristianos son herederas de la cultura de la España de época visigoda (J. A. MARAVALL, El concepto de España en la Edad Media, Madrid, 1981). El uso y abuso del neovisigotismo como uno de los fundamentos del nacionalismo español ha hecho que no se interprete correctamente este término desde el punto de vista artístico. 


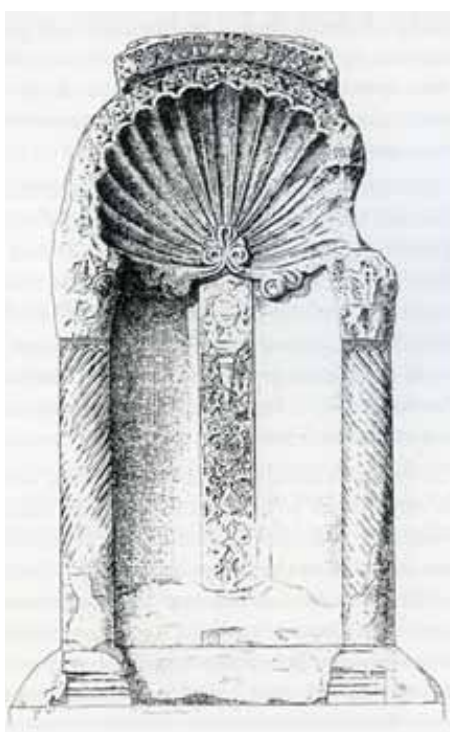

a

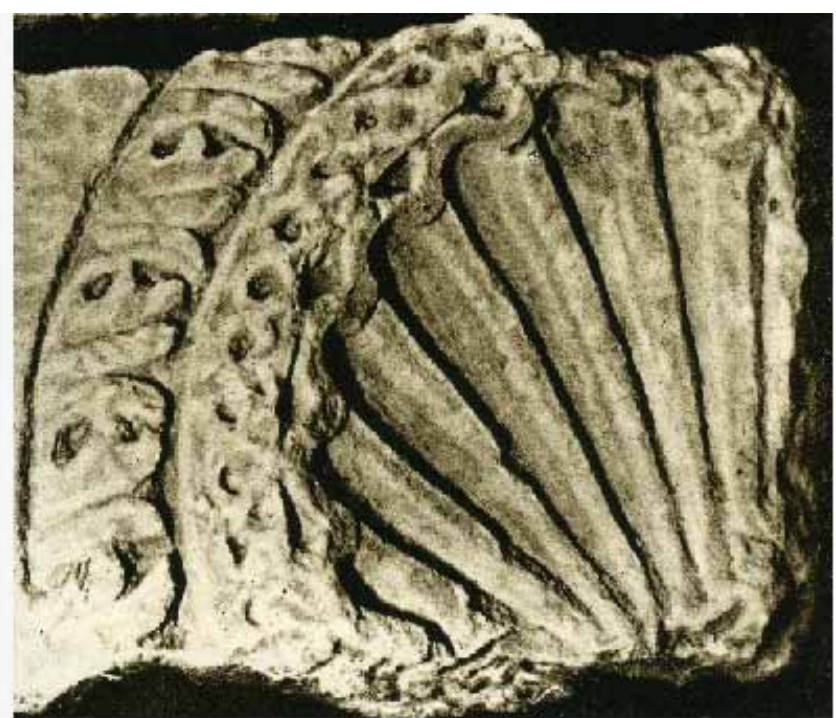

b

Fig. 4

permitirán que la mezquita estuviese ya en uso en 786-787, aunque también tenemos noticias que la edificación se prolongaría hasta la muerte de 'Abd al-Rahmān en $788^{13}$.

La mezquita cordobesa era entonces un conjunto, de planta cuadrangular, de unos 79 metros de lado, dividido en dos partes casi iguales, destinadas a patio y sala de oración. Esta última se componía de once naves perpendiculares al muro de la quibla, cada una de ellas constaba de doce tramos. Para soportar la cubierta se dispuso un orden de arcos muy elevado cuya estabilidad se consigue mediante un segundo orden de arcos, en este caso de herradura, que funcionan como un ingenioso sistema de entibo ${ }^{14}$. Como soporte de todo esto se emplearon algo más de un centenar de columnas, todas ellas de acarreo ${ }^{15}$, y los muros perimetrales, de sillería bien escuadrada.

Nada sabemos acerca del arquitecto que realizó el proyecto y dirigió las obras que materializaron la mezquita. Si analizamos técnicas y recursos que definen su trabajo, todo nos induce a afirmar que estamos ante un arquitecto formado en la tradición hispana, y quiero enfatizar este último aspecto pues es el que mejor explica el logro

13 Puede verse una excelente síntesis sobre el proceso constructivo de la mezquita de esta época en A. E. MOMPLET MÍGUEZ, El arte hispanomusulmán, Madrid, 2004, pp. 28-35.

14 Este orden de arcos de herradura nada sostienen, pero el arriostrar los pilares sustituyen a los tirantes de madera de las mezquitas de columnas, con ventaja grande para la esbeltez, belleza y monumentalidad del edificio. La altura interior, hasta la techumbre, era de 8'60 m (L. TORRES BALBÁS, “Arte hispanomusulmán”, Historia de España. España musulmana. 711-1031, dir. R. Menéndez Pidal, t. V, Madrid, 1973 p. 347).

15 El material romano reaprovechado en nuevas construcciones es una constante a partir del siglo V. Para el origen diverso del material romano de la mezquita de Córdoba vid. A. PEÑA JURADO, Estudio de la decoración arquitectónica romana y análisis del reaprovechamiento del material en la Mezquita Aljama de Córdoba, Córdoba, 2010. 
más excelente, la arcuación de entibo, cuyo precedente más directo se encuentra en el paisaje monumental de la tardorromanidad hispana. También es cierto que, después de afirmar este continuismo de lo local, los historiadores no dudan en calificar al arquitecto con otros supuestos timbres de gloria: conocedor del arte bizantino, experto en la tardorromanidad mediterránea y en la arquitectura omeya. Sinceramente todo es cierto, aunque es evidente que los referentes políticos y religiosos nada aportan salvo enmascarar una realidad material: una cultura tardoantigua que todavía subsiste. Me imagino que, cuando hablamos de arquitectura omeya, tenemos, como un paradigma excepcional de la misma, la gran Mezquita de Damasco. ¿Es posible que haya alguien capaz, después de realizar un análisis científico/técnico de este edificio, de clasificarlo como arquitectura omeya? Sí, aquellos a los que no les interesa la realidad histórica, simplemente son militantes de un credo. Pero este no es un fenómeno propio de musulmanes y "musulmanólogos", sino que también lo ha sido de cristianos y "cristianólogos".

Sobre el modelo oriental para determinados motivos de la mezquita cordobesa, su comparación formal resulta muy explícita. Calvo ha explicado como las placas nicho con forma de venera sostenida por columnas (fig. 4a) debieron tener su correspondencia en Córdoba. A este respecto no duda en incluir en esta línea los fragmentos de nicho encontrado en la mezquita de Córdoba (fig. 4b) ${ }^{16}$. Sin duda los musulmanes querían una mezquita cuyos elementos emblemáticos respondiesen a sus propios criterios, pero si observamos las dos obras, comprobamos que ambas responden a la tradición romana respectiva. La factura y la iconografía de los fragmentos cordobeses siguen la más estricta tradición hispanogoda.

\subsubsection{ARTE POSTHISPANOGODO ENTRE LOS CRISTIANOS SOMETIDOS AL PODER MUSULMÁN}

No voy a suscitar aquí otra vez toda la polémica sobre el llamado arte mozárabe o, por ser más precisos, de los mozárabes, pues lo he abordado en multitud de ocasiones ${ }^{17}$. No es mi interés repetir los términos del debate, ahora bien, me gustaría incidir en un par de ideas con respecto al tema de este apartado y referido al siglo VIII. En primer lugar señalar algo que parece obvio, pero que últimamente se está olvidando: todo grupo religioso es en principio más conservador de las formas tradicionales de su cultura que los invasores. Luego, si finalizando el siglo VIII los vencedores se caracterizan por una arquitectura posthispanogoda, la de los cristianos cuando menos sería igual.

16 S. CALVO CAPILLA, "Las primeras mezquitas de al-Andalus a través de las fuentes árabes (912/711170/785”, Al-Qantara, XXVIII, 1 (2007), pp. 143-180.

17 Mi último trabajo al respecto: I. G. BANGO TORVISO, "Un gravísimo error en la historiografía española, el empleo equivocado del término mozárabe”, El legado de Al-Andalus. El arte andalusí en los reinos de León y Castilla durante la Edad Media, Valladolid, 2007, pp. 75-88. Desde mi punto de vista al considerar lo que podría ser arte mozárabe habría que tener en cuenta lo siguiente: $1^{\circ}$ ) El término mozárabe, que significa persona con indumentaria y caracterización árabe, aparece en torno al año $1000 ; 2^{\circ}$ ) Utilizar el nombre antes de este año sería anacrónico y no se correspondería con la realidad formal. 


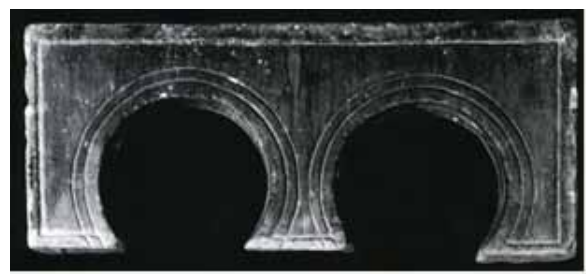

a
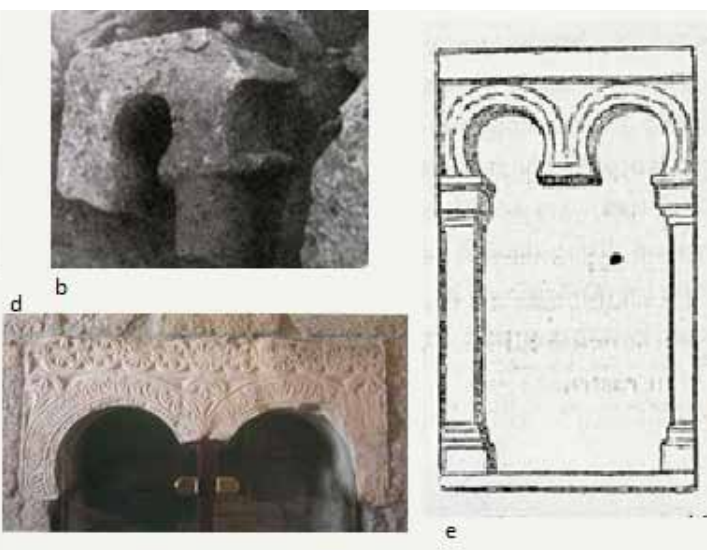

Fig. 5

Por esta razón no se entiende que un edificio de una complejidad arquitectónica como Santa Lucía del Trampal sea calificado como mozárabe ${ }^{18}$. La hipótesis que Caballero ofrece para justificar esto la resume en los siguientes términos: "Sobre la base de unas técnicas tradicionales estables, la renovación ocurriría gracias a la llegada de las innovaciones aportadas por los musulmanes en el siglo VIII" ${ }^{19}$. Desde mi punto de vista, no conozco, y menos entiendo, "las innovaciones musulmanas" que los invasores no emplean en sus edificios y sí en los de los vencidos. El Trampal se concibe perfectamente en la arquitectura tradicional romana que todavía permite construir edificios plenamente abovedados en el período hispanogodo. En consecuencia estamos ante una obra, por decirlo así, hispanogoda o, todo más, posthispanogoda.

Si bajamos al detalle del elemento arquitectónico/decorativo nos encontramos incongruencias similares. El caso de las ventanas bíforas fueron tan utilizadas por la arquitectura islámica que en nuestra lengua se conocen por una palabra de origen árabe: ajimez. Con este tipo de planteamiento no es extraño que cuando aparece en un edificio no se dude en calificarlo de mozárabe. Las placas para bíforas son una creación romana ampliamente difundidas en la época hispanogoda. Observemos el ejemplo de la placa marmórea procedente de la iglesia toledana de San Ginés (fig. 5a) ${ }^{20}$. Esta pieza hispanogoda tiene además el interés de mostrarnos un enmarque tipo alfiz ${ }^{21}$. Una variante de concepción bífora, entre las muchas soluciones que debieron existir en el mundo hispanogodo, lo presentan los ejemplos encontrados en el Tolmo de Minateda (fig. 5b) datados por su descubridora a finales del siglo VII o primeros años del $\mathrm{VIII}^{22}$. El Museo Arqueológico Nacional conserva otra pieza de este tipo (fig. 5c) que

18 L. CABALLERO ZOREDA y F. SAÉZ LARA, La iglesia mozárabe de Santa Lucía del Trampal. Alcuéscar (Cáceres): arqueología y arquitectura, Mérida, 1999.

19 Ibídem, p. 156.

20 R. BARROSO y J. MORÍN DE PABLOS, op. cit., 2007, n 434, p. 731.

21 Esta idea de enmarque de arcos es muy propia de la composición arquitectónica romana.

22 S. GUTIÉRREZ LLORET, "Algunas consideraciones sobre la cultura material de las épocas visigoda y emiral en el territorio de Tudmir”, L. CABALLERO Y P. MATEOS (eds.), Visigodos y Omeyas. Un debate entre la Antigüedad Tardía y la Alta Edad Media, Madrid, 2000, p. 113. 
con toda razón Balmaseda ha comparado el peralte de sus arcos con el citado de San Ginés. La idea del alfiz está perfectamente desarrollada, pero la diferencia es que se ha querido dotar de una riquísima decoración del tipo que hemos visto en la Estela de Ania Buturra. Procede de la Bética y ha sido clasificada como postvisigoda ${ }^{23}$. Estas obras hispanogodas y alguna más me impiden entender que los ejemplos de Lourosa (fig. 5d), compárese con San Ginés, el de Sao Torcato de Guimaraes (Fig. 5e), cualquiera de los ejemplos asturianos, aunque sean tríforos, y el tantas veces citado de San Miguel de Escalada, sean todos ellos clasificados como mozárabes. Y no es una cuestión terminológica, sino que estos autores los califican así porque los consideran, sin argumento alguno, una influencia del arte hispanoárabe. A su vez, y pido perdón por el argumento, por la presencia de estos elementos el edificio se cataloga como mozárabe. Desde mi punto de vista, no deja de ser un paralogismo, ya sea como falacia o como sofisma. Todas estas incongruencias han dado lugar a que algunos especialistas en cultura mozárabe, aunque no en el arte plástico, acompañen sus estudios con definiciones de la arquitectura mozárabe como la siguiente:

\begin{abstract}
"Todos estos ejemplos están caracterizados con arcos de herradura más o menos peraltados, con elementos decorativos similares, arcos geminados, sogueados, ventanas geminadas de un buen, aunque ruralizado estilo mozárabe de tradición visigoda y descendiente influencia islámica, sin olvidar el sutil aporte indígena en alguna de sus rosáceas y elementos solares de sus modillones." ${ }^{24}$.
\end{abstract}

Hay que ver todas las cosas que tuvieron que sintetizar los creadores de las iglesias del círculo celanovense. Absolutamente todo, salvo la duda del tipo de modillón, formaba parte de la realidad plástica hispanovisigoda de la zona.

Tal como ya he escrito en numerosas ocasiones, haríamos bien en utilizar el calificativo mozárabe con el mismo criterio que la historia de la palabra nos demuestra. Cristianos mozárabes no se constatan documentalmente hasta el entorno del año $1000^{25}$. Por entonces, estos cristianos se confunden por su indumentaria, por su arte mobiliar y por su edilicia con el arte hispanoárabe. Basta comprobar esto con el testimonio que nos ofrecen los mozárabes toledanos a partir de la conquista de la ciudad. En los territorios cristianos del Norte la cultura artística es básicamente la continuidad de la situación anterior a la invasión. Es incuestionable que cuando el arte hispanoárabe llega a su plena madurez creativa puede influir en el arte cristiano del Norte. Pero cuando esto sucede hay que tener en cuenta dos cosas fundamentales: $1^{\mathrm{a}}$, se trata de aportaciones puntuales que no definen la totalidad de la obra; $2^{\mathrm{a}}$, es muy raro que estas aportaciones anteriores al año mil sean realizadas por cristianos huidos del Sur, sino por los mismos musulmanes.

23 L. BALMASEDA, "Doble arco esculpido", Hispania Gothorum. San Ildefonso y el reino Visigodo de Toledo, Toledo, 2007, p. 518.

24 J. C. RÍOS CAMACHO, Mozarabismo en Gallaecia Altomedieval. Estudios generales y análisis desde sus fuentes documentales monásticas (siglos VIII, IX, X y XI). Tesis doctoral, Universidad de Murcia, 2009, p. 597.

25 Me remito a la obra citada en la nota $n^{\circ} 18$. 


\section{EL ARTE DE LOS CRISTIANOS EN ASTURIAS DEL 711 AL 842}

En principio, simplemente aclarar el por qué de estos dos años de referencia. El primero viene dado por el tema del coloquio, el año de la invasión, mientras que el segundo tan solo indica el año de la muerte de Alfonso II, cuyo reinado ha conseguido definir la perfecta organización del aparato del nuevo reino, a la vez que conservamos una muestra muy significativa de lo que representó el arte asturiano durante este período.

Al tener que tratar temas de estilo, me gustaría comentar previamente algo importante. Cuando analizamos el arte cristiano que va desde la invasión al románico, cometemos dos errores injustificables. Primero solemos delimitarlo con dos hitos que no son equiparables, razón por la que el resultado es erróneo o al menos tan sesgado que no resulta válido. La cronología inicial es tan contundente y sonora que nadie parece poner en duda su referencia: el año 711. El final que se nos presenta es tan obvio que ni siquiera se ha llegado a cuestionar: la aparición del estilo románico en España. Todo esto que parece tan lógico no deja de ser un disparate científico. ¿Cómo se puede delimitar un período histórico/artístico con un año por un lado, y una expresión estilística por otro? La más mínima argumentación científica exigiría que los cortes de periodización artística se hiciesen con el mismo criterio. Como el románico es un estilo importado, no surge de la experimentación artística hispana, resulta relativamente fácil separar las formas nuevas, del arte local y tradicional incluido su lógico epigonismo.

Algunos, con muy buena voluntad, han creído que superaban las dificultades definiendo este período que arranca en la mítica batalla de Guadalete (711) y termina con la introducción de las formas del románico, denominándolo prerrománico. La propuesta es horrible pues todavía es más acientífica que todo lo que llevamos dicho. Las palabras que denominan conceptos deben ser elegidas con mucho cuidado, pues, si no son idóneas, inducen a una mala interpretación del concepto. Veamos lo que significa el término prerrománico. La primera respuesta es muy evidente: aquello que existe antes de que se produzca el románico. En este sentido la expresión es muy útil pues prerrománico puede ser el arte de época hispanogoda, el insular o, llevando el significado a sus últimas consecuencias, cualquier arte anterior en el tiempo a la aparición del románico. Si tratamos el tema desde el punto de vista de la teoría de los estilos, que es lo que debe hacer un historiador del arte, las cosas cambian substancialmente. El estilo prerrománico está constituido por aquellas experiencias artísticas que terminarán generando el origen y desarrollo del estilo románico. Hoy día nadie sostiene que las experiencias arquitectónicas hispanas han dado origen al estilo románico, sino que este estilo fue importado a los diversos reinos hispanos perfectamente codificado. Así pues hay una primera deducción que no admite discusión: el arte de los cristianos hispanos desde el 711 hasta la aparición del románico no lo podemos llamar prerrománico ${ }^{26}$. Como el período que tratamos aquí es algo más restringido,

26 Esta es la razón por la que criticábamos el empleo de "prerrománico" para el arte hispanovisigodo propuesto por Caballero tal como comentábamos anteriormente. He abordado en numerosas ocasiones lo inconveniente de llamar prerrománico al arte astur, vid. una última visión del tema en I. G. BANGO 
tal como observamos en el título, pienso que nadie se puede oponer a que apliquemos el mismo criterio. Aclarado este aspecto centrémonos en el principio. Si el 711 fuese el final de un estilo y el inicio de otro, todo quedaría aclarado, pero es evidente que este cambio estilístico no se produce de manera radical. Tampoco debemos dejar de considerar que el ambiente cultural en el que se encontraban pertenecía a la misma tardorromanidad de la que procedían. Tal como hemos comentado en el apartado 1, la continuidad de lo hispanogodo bajo la hegemonía musulmana es una realidad para el siglo VIII. Si tenemos en cuenta que el dominio musulmán en Asturias se limitó a cinco o todo más seis años ${ }^{27}$, y estos corresponden a los momentos iniciales de la campaña de invasión, es lógico que los invasores no hayan dejado huella alguna en el territorio de esta época.

No me es posible entrar con todo detalle en el desarrollo que enuncia el título de mi ponencia, pero sí me gustaría tratar algunos aspectos que por sí mismos me parecen muy significativos y esclarecedores sobre la continuidad de lo hispanogodo. Continuismo que se fundamenta en los materiales disponibles, en los recursos técnicos existentes y por la voluntad expresa de los rectores de la nueva realidad política.

\subsection{UNA NUEVA REALIDAD GEOPOLÍTICA: EL REINO ASTUR}

El autor de la Crónica Albeldense, para referir el fin de la España gobernada por los visigodos, se expresa en los siguientes términos: «Rodrigo reinó tres años. En su tiempo... llamados por los enredos del país, los sarracenos ocupan España y se apoderan del reino de los godos" ${ }^{28}$. En un día de julio del año 711 tuvo lugar la batalla de Guadalete. Su principal consecuencia, tras una rápida conquista, fue el establecimiento del dominio musulmán sobre la Península Ibérica. La misma crónica nos informa de cómo en Asturias el ejército musulmán es derrotado y produce en este territorio el alumbramiento de una nueva realidad geopolítica, en este caso de confesionalidad cristiana: “...y por la divina providencia surge el reino de los astures" 29. El hecho de armas se conoce como batalla de Covadonga (722). El protagonista de esta acción bélica y primer monarca de este reino fue Pelayo (¿?-737). Así pues el resultado de la invasión creó una situación política nueva: una España gobernada por

TORVISO, Arte prerrománico hispano. El arte en la España cristiana de los siglos VI al XI, Summa Artis, vol. VIII-II, Madrid, 2001. El planteamiento general en la p. 11 y el específico del arte asturiano en pp. 305309. Así he defendido la catalogación del arte de la época de la monarquía astur como todavía tardoantiguo (I. G. BANGO TORVISO, "La cultura artística de la monarquía astur, la última manifestación de la antigüedad", en Astures. Pueblos y cultura en la frontera del Imperio Romano, cat. exp. Gijón, 1995, pp. 170-187), incluso lo he definido como el "canto del cisne de la estética romana" (I. G. BANGO TORVISO, op. cit., 2001, pp. 241-243).

27 Los detalles que explican la duración de este período pueden verse en A. BESGA MARROQUíN, Orígenes hispano-godos del reino de Asturias, Oviedo, 2000, pp. 173-177.

28 Albeldense, p. 244. Las crónicas asturianas que se citan en el presente trabajo figurarán como Rotensis (Crónica de Alfonso III rotense), Ad Sebastianum (Crónica de Alfonso III ad Sebastianum) y Albeldense (Chronica Albeldensia). Las citas, salvo indicación de lo contrario, se harán por la edición de Gil y la traducción de Moralejo (J. GIL FERNÁNDEZ, J. L. MORALEJO y J. I. RUÍZ DE LA PEÑA, Crónicas asturianas, Oviedo, 1985).

29 Ibidem, p. 247. 
una minoría musulmana y un pequeño núcleo cristiano al abrigo de las montañas del Norte $^{30}$.

Lo primero que podemos deducir de esto, es el nacimiento de una nueva realidad geopolítica: el reino de los astures. Existe un segundo aspecto, que ya existía durante la monarquía goda, pero que ahora adquiere una característica determinante, la confesionalidad cristiana. Aparece un tercer factor étnico que tendrá un enorme significado político, lo godo, aunque su peso demográfico sea mínimo o al menos en la misma proporción que existió entre los pobladores de la España de los siglos V al VIII en esta área geográfica.

Se ha querido explicar la cultura del nuevo reino a partir de estos factores étnicos, políticos y religiosos. En algunos casos pretendiendo considerar decisivo alguno de ellos, o al menos el más importante. Unas veces se ha hecho esto de manera natural y espontánea, pero no han faltado los interesados en adecuar el pasado a los planteamientos ideológicos de la realidad "politicocorrecta" de los historiadores actuales. No digamos nada de aquellos que han descubierto la existencia de un arte/artesanía de las clases populares que no está representado por el arte áulico de la corte ovetense. ¿Acaso esto no ha existido siempre en toda sociedad organizada? En cierto modo, y salvando las distancias, sería lo mismo que el sermo rusticus y el arte "oficial/académico" del aparato del estado que caracterizó el arte romano.

Las crónicas, cuyo interés visigotista es más que evidente, no dudan en considerar que el nuevo reino es el de los astures. Creo que, por esta razón, el protagonismo de los astures es indiscutible. En principio se podría decir que la tesis indigenista de Barbero y Vigil está en lo cierto ${ }^{31}$. Pero no es verdad, al menos el sentido indigenista que estos investigadores quieren dar al término. Los habitantes de la región son las astures, pero su supuesto indigenismo no debemos entenderlo como otra cosa que la realidad cultural hispanogoda que caracterizaba a los pueblos hispanos al norte del río Duero. Aunque no puedo entrar en detalles, su organización geopolítica y económica, tal vez no era excepcional, pero estaba perfectamente integrada en la administración goda. Si no fuera así no se podría entender la ocupación musulmana del territorio tal como nos informan las crónicas y confirman indubitablemente las excavaciones arqueológicas. No es necesario insistir en que el dominio de Asturias por los musulmanes se realizó por el mismo sistema que en el resto de la España visigoda. Dado el reducido número de invasores, estos dividieron sus tropas en pequeñas guarniciones que situaban en los centros "neurálgicoadministrativos" de época visigoda, desde donde controlaban los territorios y sus gentes. Estos centros eran las viejas ciudades cuya comunicación estaba asegurada por la red viaria romana. La Rotensis explica este sistema de ocupa-

\footnotetext{
30 Como es bien conocido será en Asturias donde se forme el primer núcleo de resistencia cristiana, al que luego seguirán los núcleos orientales.

31 En realidad la tesis de estos autores (A. BARBERO y M. VIGIL, Sobre los orígenes sociales de la Reconquista, Barcelona, 1974) se fundamenta en interpretar de manera interesada los estudios de C. SÁNCHEZ ALBORNOZ (España, un enigma histórico, Buenos Aires, 1956), quien a su vez no había sabido dar a la información de las fuentes una exacta lectura, sino la de refrendo definitivo de su visión ensayístico/ política del medievo hispano. Las publicaciones de estos autores son numerosísimas, por lo que me resulta imposible entrar aquí en su simple enumeración. En todo caso hago mía la crítica detallada de ambas posturas por parte de A. BESGA MARROQUÍN, op. cit., 2000, pp. 49 y ss.
} 
ción: "Por todas las provincias de España pusieron gobernadores" ${ }^{32}$. Incluso nos precisa el nombre del responsable musulmán de Asturias: "era gobernador en esta región de los asturianos, en la ciudad de Gijón, un hombre llamado Munuza, compañero de Tarik" ${ }^{33}$. En un exceso de celo especulativo se podría considerar que centrar en Gijón el dominio sarraceno era un invento cronístico, sin embargo la realidad arqueológica nos demuestra que se trata de la ciudad romana más importante del territorio, que todavía seguía manteniendo su actividad urbana, aunque fuese precariamente ${ }^{34}$. El episodio de que Munuza quisiera contraer matrimonio con la hermana de Pelayo no deja de ser un testimonio más del deseo de los invasores de integrarse en la sociedad local según venían haciendo por toda España ${ }^{35}$.

Veamos a continuación el papel de lo godo en la constitución del nuevo reino. Es importante que diferenciemos, con precisión, dos conceptos del término: $1^{\circ}$ ) persona de origen godo; $2^{\circ}$ ) godo como adjetivo que legitima el sustantivo que acompaña.

Lo primero que debemos afirmar sin ningún género de dudas, tal como ya hemos comentado, es la integración de Asturias en el aparato del estado hispanogodo, aunque nos sea imposible fijar la intensidad de esta integración ${ }^{36}$. Dado el número de godos frente a hispanorromanos en la totalidad peninsular, es lógico deducir que en la población asturiana los visigodos fueran francamente muy pocos. En segundo lugar hay que dilucidar la llegada de godos sureños motivada por la invasión. La Rotensis, al referir la derrota de don Rodrigo, nos informa: "Mas los godos perecieron parte por la espada, parte por hambre. Pero los que quedaron de estirpe regia, algunos de ellos se dirigieron a Francia, pero la mayor parte se metieron en tierra de los asturianos" ${ }^{37}$. Con razón se ha cuestionado la fiabilidad de esta información por el énfasis que pone en la idea de ex semine regio que justifique el linaje real del futuro rey de los asturianos. Sin embargo, al igual que la noticia de los hispani huidos a Francia es cierta, ¿por qué no iban a ser godos, aunque no sean de sangre real, los refugiados en Astu-

32 Rotensis, p. 200. En términos parecidos se expresaba la Albeldense, p. 173: “... regnante Iuzep in Cordoba et in Iegione cibitate Sarracenorum iussa super astures procurante Monnuzza”.

33 Ibidem.

34 Desde la publicación de la tesis doctoral de C. FERNÁNDEZ OCHOA (Asturias en la época romana, Universidad Autónoma de Madrid, 1982) y sus sucesivas publicaciones, esta investigadora ha puesto de manifiesto una romanidad importantísima en el territorio, circunstancia que varía substancialmente las especulaciones, claramente ensayísticas sobre la base de cultura material y sin duda intelectual del origen del asturorum regnum. La misma autora nos muestra una interesante imagen urbana de lo que fue el Gijón romano (C. FERNÁNDEZ OCHOA, La muralla romana de Gijón -Asturias-, Madrid, 1997).

35 Rotensis, p. 202.

36 Un análisis crítico de esta situación puede verse en A. BESGA MARROQUÍN, op. cit., 2000 , p. 168. Pero al planteamiento político de la integración de Asturias en el reino visigodo defendido por este autor, habría que añadir la persistencia de una cultura romana que, como veremos, todavía tendrá su plena continuidad durante la existencia del nuevo reino emergente. También es falso que, como no podría ser de otra manera, el territorio no estuviese plenamente cristianizado, aunque perviviesen ciertas prácticas religiosas ancestrales. Las tesis sobre el retraso de la cristianización del norte de España suelen responder a los mismos planteamientos de ideologías decimonónicas similares a los del nacionalcatolicismo. Sirva de paradigma de esto la crítica que hago sobre la visión de la no cristianización de Cantabria (I. G. BANGO TORVISO, Emiliano, un santo de la España visigoda, y el arca románica de sus reliquias, San Millán de la Cogolla, 2007, pp. 22-23).

37 Rotensis, p. 201. 
rias? Dejando aparte otras referencias de la marcha de sureños hacia las montañas del norte ${ }^{38}$, me interesa ahora señalar aquí un testimonio recogido en las capitulaciones de Mérida. Ibn Abi-1-Fayyad ${ }^{39}$ lo relata en los siguientes términos: "Y se ajustaron las paces entre ambas partes, a condición de que quedaran para los musulmanes los bienes de los muertos del día de la emboscada, los de quienes se marcharon huyendo a Galicia, y los de las iglesias, con sus ornamentos". Conviene recordar aquí que los reyes de Asturias son conocidos por las fuentes europeas coetáneas como reyes de Galicia. En conclusión, pocos o muchos y eso no importa ahora, a los visigodos que ya existían en el lugar se les añadieron algunos huidos.

Pero más importante que el número de visigodos existentes es la idea de lo godo como legitimador de una realidad política. Veamos en primer lugar cuál era esta realidad política. Ya lo hemos dicho: el reino de los astures. El territorio primigenio de este reino es Asturias, el pueblo de los astures y, en todo caso, el pueblo de los cristianos. Paradójicamente las fuentes que inspiran todo esto son las crónicas, aquellas que constituyen el fundamento del goticismo de la monarquía hispana. Se diría que los habitantes de Asturias con algunos refugiados, entre unos y otros seguramente habría también godos, constituyeron un grupo de resistencia que con el paso del tiempo podría ser considerado un reino. Pero el grupo de resistencia no se conformó con la territorialidad originaria, sino que iría extendiéndola más allá de sus fronteras naturales $^{40}$. Sean cuales fueran las circunstancias que dieron lugar a esto es evidente que necesitaba de una organización político/jurídica que legitimase su origen y desarrollo. Con la cultura e historia conocidas hasta ese momento solo había una respuesta fácil: la reivindicación de la España de los visigodos. Ahora bien, ¿qué era la España de los visigodos? Un pueblo constituido por hispanorromanos y una minoría gobernante de gente visigoda. A veces se les reconocía conjuntamente como cristianos o el pueblo cristiano. En el recién creado reino de Asturias sus habitantes eran los astures o los cristianos, solo se emplea lo godo para el linaje de los gobernantes ${ }^{41}$. Las crónicas del ciclo astur se escriben con la intención de que sean la continuidad de la crónica de los godos de Isidoro de Sevilla: "El Rey Alfonso a nuestro Sebastián, salud. Toma conocimiento de la historia de los godos, en demanda de la cual nos enviaste recado por el presbítero Dulcidio... Y dado que la crónica de los godos hasta el tiempo del glorioso rey Wamba la expuso con toda amplitud Isidoro... también nosotros, a contar desde ese tiempo, tal como le hemos oído de los antiguos y de nuestros predecesores y sabemos que es verdad, vamos a darte breve noticia" ${ }^{42}$. Continúa la narración cronística con Recesvinto hasta el rey Ordoño sin solución de continuidad. La Albeldense tiene un sentido más universal, comenzando con la descripción del mundo entero, se habla

\footnotetext{
38 Un buen análisis crítico del tema en A. BESGA MARROQUÍN, op. cit., 2000, pp. 177-186.

39 C. ÁLVAREZ DE MORALES, "Aproximación a la figura de Ibn Abi-l-Fayyad y su obra histórica", Cuadernos de Historia del Islam, 9 (1978-1979), pp. 29-127.

40 La actuación regia en este sentido se inicia con dos monarcas. Alfonso I (739-757): Xpianorum regnum extendit (Albeldense, XV, 3, p. 173). Ordoño I (850-866): Xpianorum regnum cum Dei iubamine ampliauit (Albeldense, XV, 11, p. 175).

41 Algunas veces figura el término ejército godo, pero es un empleo en clara regresión.

42 Estas palabras del comienzo de la Crónica de Alfonso III ad Sebastianum explicitan claramente la idea de continuidad del aparato historiográfico isidoriano (Ad Sebastianum, p. 195).
} 
de los reyes del pueblo godo, y no se olvida de los monarcas que reinaron en Asturias que denomina "Reyes godos de Oviedo" 43 .

No parece que se pueda dudar de la principal intención de estas crónicas: crear una relación de reyes que pertenecen a un linaje de estirpe indiscutiblemente goda. Para dar credibilidad a este linaje, la Crónica de Alfonso III ad Sebastianum, intentando dar mayor fuerza a la idea de linaje godo de algún príncipe astur con nombres indiscutibles, no le basta señalar a Recaredo, que sí que es el primer rey católico, pero no es el "primero" y el más grande por su actividad política: ex semine Leuuegildi et Recaredei regum ${ }^{44}$. Enunciada así la calidad del linaje, solo falta aportar testimonios que aseguren los nexos familiares que hagan indiscutible la relación de los primeros monarcas con los reyes indudablemente godos. En realidad sean los datos ciertos o falsos poco importa, pues las crónicas les confieren el marchamo de verosimilitud que era lo que se pretendía. Por la misma época, otra falsificación genealógica había permitido que un pipínida, Carlomagno, fuese considerado heredero directo de Constantino el Grande, y con ello crear nada menos que un imperio romano y cristiano. Esta circunstancia hizo, tal como ha demostrado Krautheimer, que lo que se ha llamado el renacimiento carolingio recuperase el arte romano del siglo IV como referencia emblemática ${ }^{45}$. Este recurrir al pasado como elemento legitimador expresado por los carolingios como Roma renovata tiene su correlato en el reino astur, su legitimación se fundamenta en el omnemque Gotorum ordinem, sicuti Toleto fuerat tal como nos ha sido explicado por la Albeldense.

\section{2. EL CONTINUISMO DE LO HISPANOGODO}

Si queremos calificar el arte de este período con criterios artísticos o estilísticos no encontramos nada que suponga una gran ruptura con el pasado y tampoco una creación de planteamientos innovadores que nos obliguen a acuñar una nueva nomencla-

43 Albeldense, p. 247.

44 García de Castro critica que yo proponga como uno de los referentes ideológicos de la nueva monarquía astur a Leovigildo, pues era un monarca arriano y anticatólico (C. GARCÍA DE CASTRO, "Notas sobre teología política en el Reino de Asturias: la inscripción del altar de Santa María de Naranco (Oviedo) y el testamento de Alfonso II", Arqueología y Territorio Medieval, 10.1 (2003), pp. 160-161 y notas 9 y 11). Con ser importante el desconocimiento del texto cronístico que acabamos de citar, el error más grave de García de Castro es desconocer el protagonismo político de Leovigildo como referente de buen gobernante y legislador reconocido incluso por la mayor parte de la iglesia católica, muy principalmente la que sigue las directrices pontificias de la época. He tratado en muchas ocasiones el papel de Leovigildo como inspirador de la teoría política de la nueva monarquía (especialmente vid: I. G. BANGO TORVISO, "Los reyes y el arte durante la Alta Edad Media: Leovigildo y Alfonso II y el arte oficial", Lecturas de Historia del Arte / Ephialte, Vitoria, 1992, pp. 19-50; Ibídem, "La creación artística como emblema de la teoría del estado en la monarquía visigoda y en la asturleonesa", Propaganda \& poder. Congreso Peninsular de Historia del Arte, Lisboa, 2001, pp. 31-46).

45 Tradicionalmente se ha interpretado que lo carolingio representaba una recuperación del mundo clásico, pretendiendo entender el renacimiento carolingio como si fuese el renacimiento por antonomasia. Pero esta no era la correcta interpretación de la recuperación del pasado romano, solo se entendía como un referente legitimador político y religioso. En este sentido la Roma renovata era la del siglo IV (R. KRAUTHEIMER, "The Carolingian Renaissance of Early Christian Architecture", Studies in Early Christian Medieval and Renaissance Art, Nueva York-Londres, 1969, pp. 203-256). 
tura estilística. Sin embargo debemos reconocer que sí se ha hecho, aunque en la mayoría de las ocasiones por un mal conocimiento de la teoría historiográfica del arte.

Cuando utilizamos el término arte hispanogodo, vuelvo a reiterar aquí que nos referimos a la cultura hispana de la época que gobernaban los visigodos. Este hispanogoticismo no tiene el mismo carácter que se da a un linaje gótico o godo como referente étnico. Así en Asturias se pretendió, fuese verdad o no como ya hemos comentado, que sus reyes fuesen del linaje de los godos. La cultura material fue la misma que existía antes del 711, es decir la hispanogoda. Pero sobre esto debemos de aclarar algunos aspectos. El mundo tardorromano que pervivía bajo la monarquía goda, especialmente en lo que se conoce tópicamente como sermo rusticus, no era absolutamente uniforme. La intensidad de la romanidad, las condiciones de los materiales locales y la economía marcaban claramente lo que el lenguaje decimonónico denominaría "escuelas". Creo que, a estas alturas de nuestro conocimiento del territorio astur, no podemos negar ni la integración en la administración hispanogoda ni la importancia de la tardorromanidad existente. Aunque las emigraciones ocasionadas por la invasión, por pequeñas que fuesen y esto está todavía por probar, seguramente introdujeron algunas experiencias de otros territorios hispanos.

Hay un aspecto sociológico que debe ser considerado por su decisiva importancia: la constitución de un reino con el correspondiente aparato de representación. La primera consecuencia fue la constitución de un centro neurálgico de la situación geopolítica que se había creado. Se sucederán así cuatro capitales: Gijón, Cangas, Pravia y Oviedo.

La Crónica de Alfonso III, en sus dos versiones, nos informa de lo ocurrido tras la derrota de Covadonga en los siguientes términos: "Mas el ya dicho Munuza, al saber del hecho, escapó de la ciudad marítima de Gijón y se dio a la fuga" "46. A continuación la misma crónica, también en sus dos versiones, señala una actividad pobladora y una restauración eclesiástica: Tunc populatur patria, restauratur ecclessia et omnes in comune gratias referunt Deo dicentes: Sit nomem Domini benedictum, qui confortat in se credentes et dextruit inprouas gentes ${ }^{47}$. Sea cual fuere el nivel de la batalla de Covadonga, la realidad indiscutible es que produjo el principio del fin de la ciudad romana que había sido el punto estratégico y económico de Asturias, Gijón. La salida del jefe musulmán no supuso el establecimiento de la nueva cúpula de poder cristiano en la urbe gijonesa, nunca más volverá a ser tenida como referente político. En principio, porque la vía romana permitía la llegada de un ejército invasor con facilidad. Cuando la lejanía de este peligro sea una realidad, el carácter marítimo de Gijón provocará nuevos peligros, los normandos. Gijón, como gran ciudad que había sido, apenas supervivirá y sus magníficos materiales de construcción servirán de cantera a los proyectos del nuevo estado ${ }^{48}$. El lugar elegido como capital es Cangas, una zona muy romanizada ${ }^{49}$. El otro fenómeno que se ha producido tiene una gran importancia:

46 Rotensis, 11, p. 130. In ciuitate Gegione...relicta urbe fugam arripuit (Ad Sebastianum, 11, p. 131).

47 Ibídem.

48 I. G. BANGO TORVISO, op. cit., 1995, pp. 172-175.

49 Aunque se atribuye la elección de este lugar a las vinculaciones familiares que el monarca tenía aquí, también debió ser decisivo su carácter de fortaleza natural que facilitaba la defensa de la capital frente ataques 
populatur patria, restauratur ecclessia. Sin duda, los hechos bélicos ocurridos y el no restablecimiento total de Gijón, así como la ubicación de un nuevo centro estratégico del poder, obligó a tareas de reorganización territorial de la población, tanto político-administrativa como religiosa. Mientras que esta primera actividad pobladora se refiere a un primer momento, en la época del mismo Pelayo, se producirá después, bajo el reinado de Alfonso I (739-757), una segunda repoblación más compleja que se compaginará con la actuación regia en el territorio del valle del Duero y su población ${ }^{50}$. Con Silo (774-783) se procederá a un nuevo cambio de la sede regia, estableciéndose en Pravia. Una vez más se ha elegido un viejo asentamiento romano ${ }^{51}$.

Pero sin duda el hecho más decisivo del nuevo reino astur fue la elección de Alfonso II como rey. Su ideario político tendrá una manifestación cultural absolutamente emblemática: concretar su teoría del reino en una capital. Cuando yo empecé mis estudios sobre el tema, la visigotización del reino astur se consideraba una creación de Alfonso III y su círculo de colaboradores, perfectamente manifestado en las célebres crónicas $^{52}$. No se entiende que se hubiera podido llegar a esta afirmación, cuando la tozudez de los hechos expuestos por los mismos cronistas señalaba todo lo contrario. Alfonso cumple con todos los requisitos legales para ser un auténtico monarca a la goda: es ungido ${ }^{53}$. Si este era el principio protocolario para ser considerado un rey visigodo, aunque sea "godo de Oviedo", también se requería un protocolo para el monarca que hiciese creíble su condición. Etiqueta y protocolo hacían referencia a la imagen y al ceremonial; pero, desde el punto de vista de la propaganda política, no había nada más importante para el imaginario popular que el escenario arquitectónico y monumental que debía de tener la capital del Asturorum regnum. Con este fin Alfonso estableció el solium, entendamos este término en sentido amplio, la capital del reino, en Oviedo. El conocido texto de la Albeldense deja muy claro la intención de este escenario regio: -después de referir la labor edilicia promovida por Alfonso II- omnemque Gotorum ordinem, sicuti Toleto fuerat, tam in ecclesia quam palatio in

exteriores (J. I. RUÍZ DE LA PEÑA SOLAR, La monarquía asturiana, Oviedo, 2001, pp. 40-41). Se ha dicho que pudo ser un vicus viarius de época romana (J. A. GUTIÉRREZ GONZÁLEZ, "La formación del territorio de Asturias en el período de la monarquía asturiana", en L. ARIAS (coord.), Enciclopedia del Prerrománico en Asturias. Asturias, vol. I, Aguilar de Campoo, 2007, pp. 37-40).

50 No me interesa entrar en la complejidad historiográfica de las tesis de Albornoz y de Menéndez Pidal, por no citar las posturas más recientes. Para un estado crítico de esta polémica vid. J. I. RUÍZ LA PEÑA SOLAR, op. cit., 2001, pp. 65-74.

51 Sin duda las circunstancias que motivaron el traslado de la capital fueron las favorables condiciones del lugar así como "una mayor proximidad a una Galicia de fidelidad claudicante a la autoridad de los monarcas astures" (Ibidem, p. 109). La romanidad de este núcleo se explica por encontrarse en el área de la antigua Flavionavia (J. A. GUTIÉRREZ GONZÁLEZ, op. cit., 2007, p. 41).

52 Siempre he defendido en todas mis publicaciones este proceso de visigotización de la monarquía astur desarrollado especialmente por Alfonso II (I. G. BANGO TORVISO, "L'Ordo gotorum et sa survivance dans l'Espagne du Haut Moyen Age", Revue de l'Art, 70 (1985), pp. 9-20).

53 El hecho de que la información cronística haga hincapié en esta ceremonia me parece todo un síntoma de que teoría del reino y protocolo regio han llegado a su total definición según los cánones más tradicionales de la monarquía goda y católica (I. G. BANGO TORVISO, "Hunctus rex. El imaginario de la unción de los reyes en la España de los siglos VI al XI", Homenaje a Manuel Bendala, Universidad Autónoma de Madrid, en prensa). 
Ouetao cuncta statuit ${ }^{54}$. De la trascendencia del papel jugado por Alfonso II, forjando un reino, resulta un testimonio indiscutible el que la Crónica de Alfonso III lo proclamase ADEFONSUS MAGNUS ${ }^{55}$. La memoria de los pueblos solo suele conferir el calificativo de Grande a un monarca cuya intervención personal ha sido decisiva para la historia de la nación. Tal es el caso de Alfredo el Grande, Carlomagno, etc.

Conviene que recordemos ahora lo que decíamos antes del concepto de "visigotización". La imagen del rey astur debe corresponderse, por las razones que ya hemos expuesto, con la del rey visigodo tanto en la idea del linaje como en su iconografía. El linaje es la sangre, pero esta, siendo real o no su verdadero origen familiar, no se plasma en una imagen plástica. La iconografía es otra cosa muy distinta. Tal como hemos comentado, nos referimos a cultura material, tanto mueble como inmueble, y esta se corresponde a lo que hemos llamado cultura hispanogoda. Por desgracia para la comprensión del fenómeno histórico, muchos historiadores confunden los términos y los contenidos. En la última parte de esta ponencia quisiera analizar, aunque sea muy brevemente algunas obras que me permitan realizar la tesis final de mi pequeña aportación.

\subsubsection{La inscripción de Santa Cruz de Cangas}

Sobre las obras realizadas por Favila (737-739) en Cangas de Onís la Rotense nos ofrece un precioso testimonio: "Tras él -Pelayo- su hijo Favila ocupó el puesto de su padre. Edificó en una obra admirable, una basílica en honor de la Santa Cruz" ${ }^{56}$. El edificio se podría considerar la primera manifestación monumental del reino de los astures, nada más emblemático que un templo de la nueva capital y nada menos que surgida bajo el patrocinio de Favila y su esposa Froliuba. Su consagración fue llevada a cabo por el obispo Asterio el domingo 27 de octubre de 737. Todo fue destruido en el año 1936, pero la inscripción la conocemos por una vieja fotografía del siglo XIX (fig. 6a) y por una copia fiel realizada por Roberto Frassinelli para la Comisión de Monumentos Histórico Artísticos de la provincia de Oviedo (1844) (fig. 6b) ${ }^{57}$. Se ha discutido mucho sobre la forma y significado de este templo; el tema es fascinante, pero sobre tópicos más que evidentes todo lo que se ha dicho hasta hoy resulta meramente especulativo y nada trascendente desde el punto de vista artístico ${ }^{58}$. El que se haya edificado el templo sobre una vieja construcción megalítica no es una característica exclusiva de lo asturiano, es un lugar común en la continuidad cristianizada de

54 Albeldense, XV, 9, p. 174. Parece increíble que todavía haya quien dude de que el texto se refiere a la actuación real del monarca, que el visigotismo promovido por Alfonso II es obra suya. A este respecto es significativa la interpretación que se hace de este texto: "una situación que quizás deba atribuirse más bien al ideal de Alfonso III que al del rey casto” (J. A. GUTIÉRREZ GONZÁLEZ, op. cit., 2007, p. 33).

55 Rotensis, p. 138.

56 Rotensis, p. 202.

57 Originalmente se encontraba en el arco triunfal del templo y su tamaño era el siguiente: 0'68 x 0'89 m. Para un estudio del epígrafe y el estado de la cuestión vid. el trabajo de F. DIEGO SANTOS, Inscripciones medievales de Asturias, Oviedo, 1994, n 253, pp. 226-227.

58 Un buen estado de la cuestión puede verse en las siguientes obras: C. GARCÍA DE CASTRO, Arqueología cristiana de la Alta Edad Media en Asturias, Oviedo, 1995, pp. 181-184; L. ARIAS PÁRAMO, Enciclopedia del Prerrománico en Asturias. Asturias, vol. I, Aguilar de Campoo, pp. 137-142. 


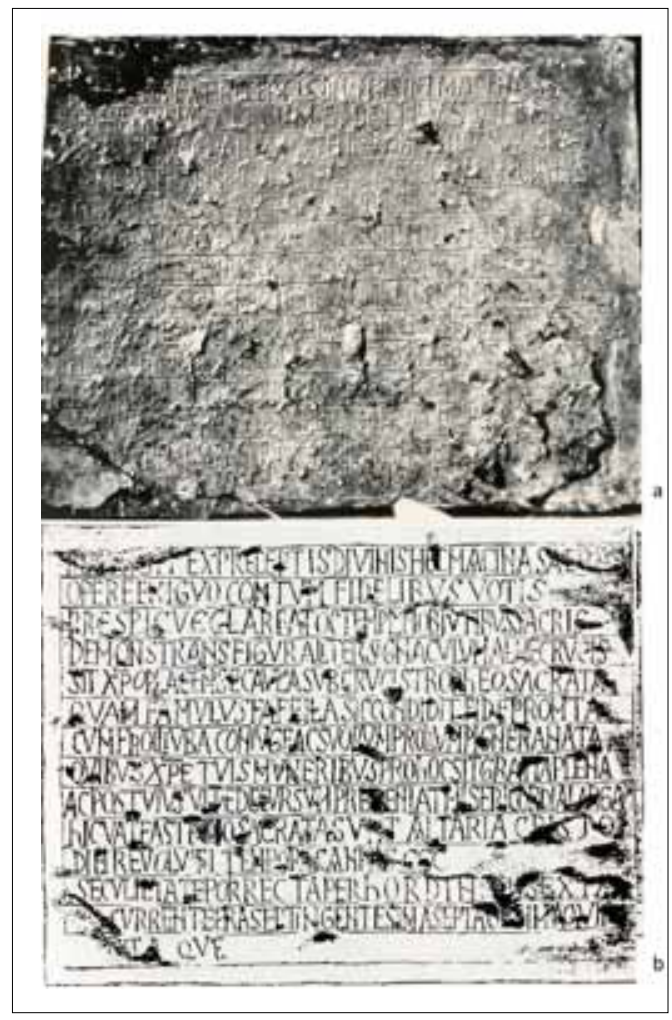

Fig. 6

los antiguos centros de culto ${ }^{59}$. Desde mi punto de vista, o al menos para el interés de mi ponencia, es el contenido del epígrafe el que me interesa. A continuación presento la lectura de Santos que me parece más detallada y me merece absoluto crédito. En todo caso la he cotejado con la libérrima del maestro Díaz y Díaz ${ }^{60}$. La lectura es la siguiente:

Resurgit ex pr(a)eceptis diuinis h(a)ec mac(h)ina sacra / opere exiguo comtum fidelibus uotis / prespicue clareat $(\mathrm{h})$ oc templum obtutibus sacris / demostrans figuraliter signaculum alm(a)e crucis / sit Xr(ist)o placens (ha)ec aula sub crucis troph(a)eo sacrata / quam famulus Faffila sic condidit fide prom(p)ta / cum Froiliuba coniuge ac suorum prolium pignera nata / quibus Xr(ist)e tuis muneribus pro hoc sit gratia plena / ac post $(\mathrm{h})$ uius vit(a)e decursum preveniat misericordia larga / hic vate Astemo sacrata sunt altaria $C(\mathrm{~h})$ risto / diei reuoluti temporis anni CCC / s(a)eculi (a)etate porrecta per hordinem sexta / currente (a)era septingentesima sept(u)agésima quin / taque ${ }^{61}$.

\footnotetext{
59 Por esta razón debemos ser muy cuidadosos en aplicar la teoría genérica de este tema a esta construcción, pues por la fecha y contenido del epígrafe podría ser absolutamente gratuita.

60 M. C. DÍAZ y DÍAZ, Asturias en el siglo VIII. La cultura literaria, Oviedo, 2001, p. 32.

61 F. DIEGO SANTOS, op. cit., 1994, nº 253, pp. 226-227.
} 
Traducción de Santos:

"Por orden divina vuelve a levantarse (resurge) este edificio sagrado, de construcción sencilla, pero embellecido por las ofrendas de la fe, que este templo resplandezca esplendoroso ante las miradas piadosas. Cual representa esta morada el signo de la cruz simbólicamente, que sea grata a Cristo ya consagrada bajo el trofeo de la Cruz. Tu siervo Favila viva así la construyó, con Froiliuba, su esposa, y las prendas de su estirpe, sus hijos; a ellos, mediante tus dones, Cristo, les sea dado por su obra plenitud de gracia, y tras el decurso de esta vida, los acoja el seno de tu misericordia. Por el obispo Asterio, fueron consagrados a Cristo aquí estos altares, el día trescientos de tiempo recorrido del año ( 27 de octubre), en el curso sucesivo de la sexta edad del mundo, corriendo la era setecientos setenta y cinco (737 d. de Cristo)" 62 .

En primer lugar debemos dejar claro que no se trata de un edificio hecho de nuevo, sino que el verbo empleado, resurgo, incide de manera muy clara y precisa en la idea de repetir la acción del verbo surgo. Por esta razón no veo por qué no se ha de utilizar las acepciones fundamentales de este verbo: re-surgir, re-nacer, volver a ponerse en pie. En este sentido responde al espíritu de la crónica que habla de la reorganización del territorio, el cambio de capital es un indicio, y de la restauración eclesiástica. En resumidas cuentas, toda una continuidad sobre lo que ya existía ${ }^{63}$. La expresión haec aula sub crucis troph(a)eo sacrata, ha dado pie a una extraña interpretación: el templo tenía planta de cruz ${ }^{64}$. El texto no dice otra cosa que la iglesia ha sido consagrada "bajo el trofeo de la cruz", entendido trofeo como el trophaeum romano, símbolo de la victoria. La intervención de un obispo y la celebración de la consagración en domingo confirman el cumplimiento estricto de la normativa canónica. Pero todavía podemos ir más lejos, y en ello ha sido muy preciso, Díaz y Díaz: se trata de una muestra literaria, propia de una persona medianamente cultivada que se mantiene apegada a una tradición anterior ${ }^{65}$.

\subsubsection{El antiguo caligrama romano. El laberinto del rey Silo en Pravia}

Avancemos un poco más y situémonos en una nueva sede regia, Pravia. La Albeldense de manera muy breve nos informa de este hecho: "Silo reinó nueve años. Cuando éste recibió el reino, asentó la capital (solium) en Pravia" "66. En Santianes de Pravia se conservaba una inscripción escrita con forma laberíntica. Fue destruida durante unas

62 Díaz y Díaz interpreta por domingo 27 de octubre de 737 (M. C. DÍAZ y DÍAZ, op. cit., 2001, p. 33).

63 Si existiera intención en la construcción de un templo cristiano sobre un viejo espacio ritual, tal como hemos comentado anteriormente, es evidente que entonces habría que relacionarla con el primer templo, no con este erigido por Favila. Este aspecto es importante, pues el epígrafe es uno de los hitos que apoya la teoría de un indigenismo pagano en Asturias hasta los tiempos del Asturorum regnum.

64 No solo se deducía esto, sino que se iba más lejos considerando que la iglesia, por la supuesta forma de su planta, se catalogaba como un tipo de edificio "visigodo". Esta postura, defendida por Schlunk (H. SCHLUNK, "Arte asturiano", Ars Hispaniae, vol. II, Madrid, 1947, p. 327), increíblemente todavía sigue siendo sostenida por algún investigador que no ha prestado mucha atención al epígrafe.

65 M. C. DÍAZ y DÍAZ, op. cit., 2001, pp. 40-41.

66 Albeldense, 6, p. 248. 


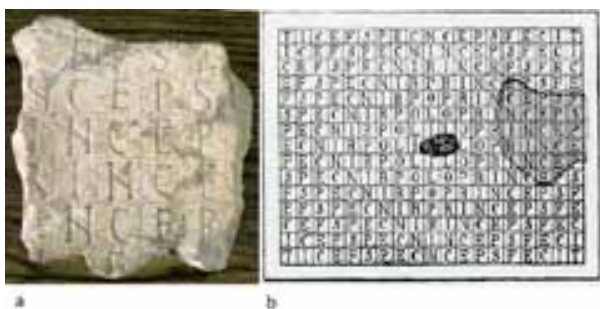

T I C E F S P E C E P S F E C I T

I C E F S P E C N C E P S F E C I

C E F S P E C N I N C E P S F E C

E F S P E C N I R I N C E P S F E

F S P E C N I R P R I N C E P S F

$S$ P E C N I RP OP R I NCE P S

P E C N I RP OLOPRI N C E P

E C N I R P OL I L OP R I N C E

C N I R P OLI S I L OP R I N C

E C N I R P O L I L OP R I N C E

P E C N I RPOLOPRINCEP

S P E C N I RP OPR I NCEP S

F S P E C N I R P R I N C E P S F

E F S P E C N I R I N C E P S F E

C E F S P E C N I N C E P S F E C

I C E F S P E C N C E P S F E C I

T I C E F S P E C E P S F E C I T

Fig. 7

obras del siglo XVII. Se han conservado dos pequeños fragmentos, el más grande fue descubierto en el año 1975 (fig. 7a). Siguiendo el esquema de Risco, Santos ha hecho una reconstrucción ideal (fig. 7b) ${ }^{67}$. El laberinto se componía de un damero de 19 verticales y 15 horizontales, con unas teóricas 285 casillas, donde a partir del centro se repetía una frase tan sencilla como: SILO PRINCEPS FECIT. Aunque Díaz y Díaz en el texto parece estar de acuerdo con la versión de casillas tradicional, en su propuesta del original ofrece una versión de 17 verticales y otras tantas horizontales ${ }^{68}$. He reproducido el esquema de Díaz respetando la proporción de las letras y del interlineado que contemplamos en los restos conservados (fig. 7c) ${ }^{69}$, resultando un epígrafe cuadrado más acorde con los llamados cuadrados mágicos.

Los epígrafes laberínticos de este tipo tienen en la basílica de San Reparato de Orleansville su manifestación más antigua documentada. Aunque no conservamos ejemplos hispanogodos, las estrechas relaciones del arte de esta época con el norte de África y muy especialmente con Orleansville, hacen más que posible su existencia. Esta se confirmaría por su uso en diferentes soportes durante el período altomedieval hispano. La fórmula fue empleada en libros, como uno del 812, hoy desaparecido, o en otros códices de Alfonso III. De un hermoso efectismo cromático y ornamental es

67 F. DIEGO SANTOS, op. cit., 1994, nº 175, p. 172.

68 M. C. DÍAZ y DÍAZ,op. cit., 2001, p. 54.

69 El perfil que reproduce Díaz y Díaz se corresponde con un rectángulo, pues no tiene en cuenta el tamaño de las casillas conservadas. 


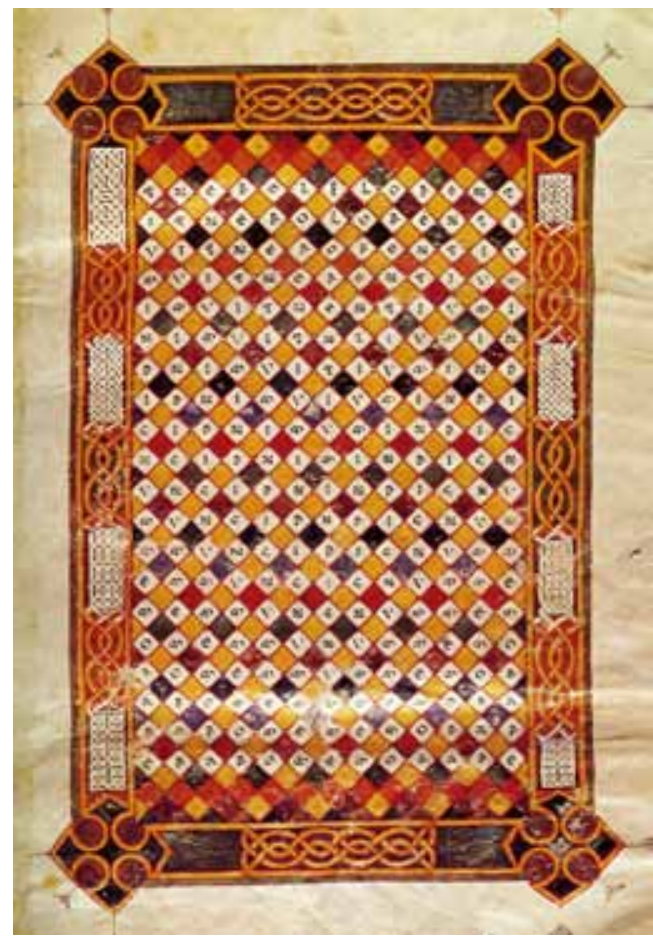

Fig. 8

el representado en los Moralia in Job, realizado por Florencio en el monasterio de Valeránica, el año 945 (fig. 8). Esta leyenda laberíntica de Valeránica, aunque reproduce un número considerable de casillas en losange, solo 260 están pintadas en blanco, y son utilizadas para las letras que forman el texto que se quiere reproducir: FLORENTIUS INDIGNUM MEMORARE. John Williams, con toda razón, ha indicado como nuestro pintor, señalando los ejemplos asturianos, es el continuador de una tradición bien documentada en España ${ }^{70}$. La composición del laberinto responde a dos criterios diferentes. En Pravia, a partir de la S que constituye el centro, se podía leer hacia los vértices, formando cuantos ángulos rectos se desee, formándose rombos concéntricos, de los cuales los siete primeros son cerrados. Por otro lado, el significado del texto y su disposición, evocando la dirección de los cuatro puntos cardinales, que son a la vez representación de los cuatro ríos del paraíso, que viene a ser el nombre del rey ${ }^{71}$. Sin duda la composición de Florencio es más simple. A partir de la casilla central de la primera línea, donde se coloca la F, se puede ir leyendo hacia la derecha o la izquierda. Cada casilla de esta línea superior permite completar la lectura en su descendiente vertical correspondiente. A diferencia de los rombos de Silo, aquí solo vemos ángulos rectos, de lados que repiten la misma letra, con el vértice en la columna central.

70 J. WILLIAMS, Manuscrits espagnols du Haut Moyen Age, Paris, 1977, p. 50.

71 M. C. DÍAZ y DÍAZ, op. cit., 2001, p. 54. 


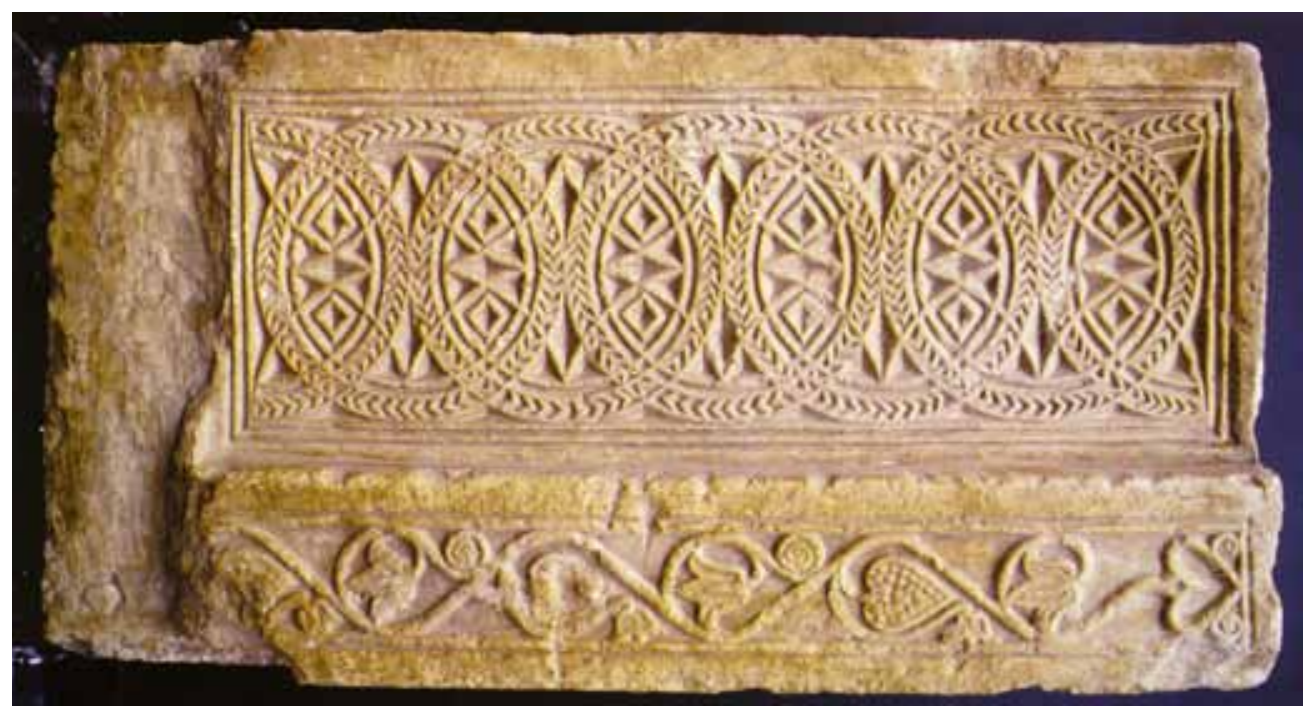

Fig. 9

Toda esta variedad compositiva, realizada en diversos soportes, habla por sí sola de una técnica bien conocida en Asturias, que tuvo su origen más inmediato en la cultura hispanogoda ${ }^{72}$.

No puedo entrar en la compleja problemática de la forma y cronología del templo de Pravia, aunque sí me gustaría recordar aquí que ahora las posturas se han radicalizado: para unos corresponde a la época del monarca, mientras que otros retrasan su cronología al siglo $\mathrm{X}^{73}$. Han aparecido nuevos fragmentos de relieves que vienen a engrosar la nómina de escultura monumental que encabezaban los dos fragmentos de canceles conservados en El Pitu (fig. 9). En teoría el epígrafe de la cifra silana confirma que el matrimonio real construyó el templo ${ }^{74}$. Tampoco se puede negar la existencia de una o varias reconstrucciones posteriores. Yo mismo, viendo la manera de entestar el intercolumnio con la aplicación de columnas, he considerado que el templo ha sido muy rehecho en un período inercial asturiano en el que es muy difícil precisar las partes que puedan corresponder a la primera fase ${ }^{75}$. Ante esta compleji-

72 El mismo acróstico de Mauregato es un recurso más de la variedad de modelos conocidos durante la monarquía astur. Con los conocidos carmina figurata constituyen una muestra de la rica variedad del caligrama romano, que tendrá una particular redefinición por el arte moderno.

73 Para un apurado y completo estado de la cuestión del edificio ver el trabajo de L. CABALLERO ZOREDA y J. I. MURILLO FRAGERO, "San Juan de Evangelista de Santianes de Pravia. La obra del rey Silo. Una supuesta iglesia construida y decorada hacia el año 900", L. CABALLERO ZOREDA et alii, Las iglesias asturianas de Pravia y Tuñón. Arqueología de la arquitectura, Madrid, 2010, pp. 11-90.

74 Evidentemente cualquier epígrafe ha podido ser trasladado de otro sitio al lugar donde se ha hallado.

75 I. G. BANGO TORVISO, op. cit., 2001, p. 250. Como ya señalé en su momento la manera de combinar un intercolumnio de pilares teniendo columnas en el enteste correspondiente a la parte oriental es una solución que se realiza en algunas iglesias de las primeras manifestaciones del románico pleno gallego. En éstas el recuerdo de lo asturiano está muy presente, tal como podemos ver en San Pedro de Ansemil (I. G. BANGO TORVISO, Arquitectura románica en Pontevedra, La Coruña, 1979, pp. 79 y 96-98). 
dad de datación de las fases constructivas, aclaremos lo que pueden aportar los canceles citados. Las propuestas van desde una clasificación como obras hispanogodas hasta mozárabes. A estas dos propuestas habría que añadir un origen sasánida, que bien pudo seguir un intermediario como lo que llaman "bizantino de los siglos V-VII" o el mundo omeya. De lo sasánida y su posible presencia en lo hispano altomedieval se han ocupado otras ponencias de estas Jornadas, pero en todo caso sí me gustaría afirmar algo: primero, es necesario clarificar la auténtica cronología de lo sasánida de posible referencia; segundo, si las señaladas "formas" sasánidas en el mundo asturiano reproducen unas características propias de una factura monumental o a través de un soporte mobiliar ${ }^{76}$. Si tenemos en cuenta la tendencia geometrizante, el trenzado o el tallo sinuoso con hojas y racimos, todo ello está presente en la estela de Ania Buturra. Desde entonces, por lo menos, es posible que en cualquier momento se pudiera hacer una pieza como esta ${ }^{77}$. La única diferencia icónica es la hoja que alterna con el racimo, pero es tan corriente dentro de la escultura romana de los siglos IV al VI que no merece la pena detenerse más en ello. Estos relieves pertenecen a la plástica más tradicional trasmitida a la posteridad por una de las diversas variantes de la escultura hispanogoda.

\subsubsection{Pizarra de Carrio. Magia y fe en el conjuro del Campesino hispanogodo}

Se trata de una pizarra que mide 22 x $26 \mathrm{~cm}$ y con forma casi trapezoidal. Fue hallada por unos labradores de manera ocasional en Carrio, cerca de Villayón, en las proximidades del río $\mathrm{Navia}^{78}$. Se trata del texto de un conjuro destinado a proteger los terrenos y plantaciones contra una calamidad como es el pedrisco. Fue enterrada en un campo de labor con la función de protegerlo de este tipo de desastres, y aquí debió ser encontrada por sus descubridores (fig. 10). A continuación ofrecemos la traducción de Díaz y Díaz ${ }^{79}$, introduciendo algunas indicaciones de la propuesta de Velázquez ${ }^{80}$ :

"Por esto desde el día ${ }^{81}[\ldots]$ recibí nonias que son necesarias sobre $[\ldots]$ de los habitantes y labradores, el siervo de Dios Cecit $[\ldots]^{82}$. Os conjuro a vosotros todos los patriarcas Miguel, Gabriel, Cecitel, Uriel, Rafael, Ananiel, Marmoniel, que retenéis

76 En este sentido, pese a que se enuncia esta problemática, sin resolverla satisfactoriamente, no se duda en atribuir este origen (J. M. HOPPE, "Le corpus de la sculpture visigothique. Libre parcours et essai d'interpretation", L. CABALLERO y P. MATEOS (edit.), Visigodos y Omeyas. Un debate entre la Antigüedad Tardía y la Alta Edad Media, Madrid, 2000, pp. 313-315). Sobre la realidad de estas supuestos orientalismos y la realidad de su presencia en la plástica hispana de esta época resultó paradigmática la comunicación que presentaron Uscatescu y Ruiz Souza, texto que figura en esta edición de las Jornadas.

77 Ni por su técnica, ni por su estilo y mucho menos por su iconografía es posible datar con precisión una obra como esta.

78 Entregada por sus descubridores a Gómez Moreno, se han realizado diferentes lecturas hasta nuestros días. Incluso en alguna de estas se ha llegado a decir que en ella se testimoniaba la existencia de "Gijón como ciudad marítima".

79 M. C. DÍAZ y DÍAZ, op. cit., 2001, pp. 142-143.

80 I. VELÁZQUEZ SORIANO, "Las pizarras visigodas: edición crítica y estudio”, Antigüedad y cristianismo. Monografías históricas sobre la Antigüedad tardia, 6 (1989), pp. 312-314, nº 104.

81 "Para el agua en mala hora" (Ibidem).

82 "del siervo de Dios Cecit" (Ibídem). 


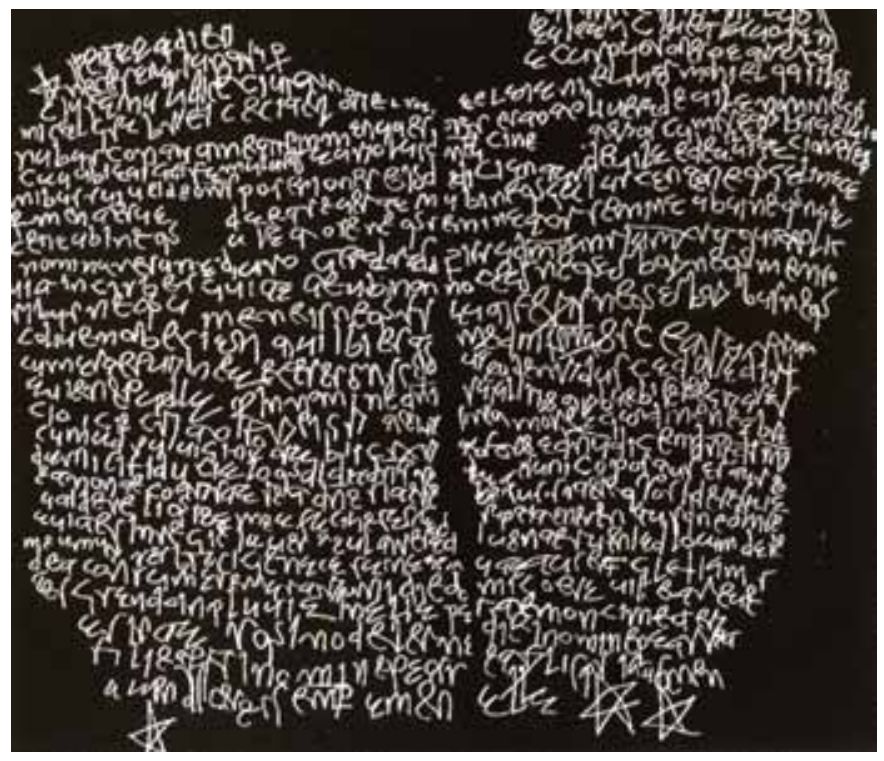

Fig. 10

las nubes en vuestras manos. Sea libre la villa de nombre [...]cau donde habita el siervo de Dios Auriolo, [y el monte] junto a su cementerio con sus hermanos y vecinos, [y sean libres también] todas las posesiones de éste; sea expulsado de la villa y de las casas; por los montes vaya y vuelva, donde ni el gallo canta ni la gallina cacarea, donde no hay quien are ni sembrador siembre, donde ningún nombre resuena. Te conjuro, Satán, por nuestro Señor Jesucristo, que se confinó en la ciudad de Cirbes, a que no perjudiques ni a los árboles ni a los segadores ni a los viñedos ni a los frutales ni a los árboles [infructuosos], ni a cualquier cosa que se te ponga por delante:[...] allí está el señor [con su] cetro grande [en la mano], con arte...? ${ }^{83}[\ldots]$ a la hora del día $[\ldots]$ en la cilla ${ }^{84}[\ldots]$ del señor [...] vecino [para decir] la oración de san Cristóbal; san Cristóbal desde este momento [aparta de nosotros] el granizo, [...] los suyos. Oró san Cristóbal diciendo: Señor, Dios mío, dame confianza de hablar. Dijo el Señor: Tal como has pedido así (será). Y no te afligiré. [...] Dios, o el lugar o la región o la ciudad donde (haya alguna) de mis reliquias [dales] la gracia (de que recojan). Señor, todos los habitantes de la región el trabajo de su cultivo con abundancia. Llegó al lugar [Cristóbal], dobló sus rodillas y le fue amputada su cabeza y se consumó el martirio en domingo, en la hora sétima. Y se vuelve el granizo en lluvia en la otra parte del monte del cementerio [y así sigue] esta hasta el día de hoy. En el nombre del Padre y del Hijo y del Espíritu, en el nombre del Padre y del Hijo y del Espíritu Santo. Amén, amén, por siempre amén, aleluya".

\footnotetext{
83 "Arte furinea (i)" (Ibidem).

84 “Celda" (Ibidem).
} 
Estos exorcismos tienen un origen griego, pasando después al mundo romano, y en España están perfectamente documentados en la época hispanogoda ${ }^{85}$. El conjuro a ángeles o patriarcas, reales o desconocidos, pues su expresión se confunde ("Os conjuro a vosotros todos los patriarcas Miguel, Gabriel, Cecitel, Uriel, Rafael, Ananiel, Marmoniel, que retenéis las nubes en vuestras manos"), podría interpretarse por una sociedad poco cristianizada. En todo caso esta confusa mezcla de lo cristiano con lo mágico ancestral no solo es propia de este momento, sino que ya se produjo entre los primeros cristianos siglos antes de la creación de nuestra pizarra. Ya Clemente de Alejandría (Strom.,VI 31, 1-3) se refería a ello: "afirman algunos que las plagas, así como el granizo; las tormentas y otros fenómenos análogos derivan no solo del desorden de la materia, sino que se originan por cierta agitación de los espíritus y de los ángeles malvados" ${ }^{\prime 6}$. Este cristianismo mediatizado por fórmulas mágicas paganas ya había sido perseguido por los padres de los concilios toledanos.

Sobre la materia y la forma de la escritura los expertos parecen coincidir en un origen en tierras de Salamanca o Ávila. Esto podría hacernos pensar en las citadas migraciones de gente del sur hacia el norte, tal como ya hemos comentado al tratar de las capitulaciones de Mérida. Pero lo que a mí me interesa enfatizar aquí es cómo los campesinos siguen usando estos tradicionales amuletos telúricos protectores de campos y cosechas. Con esto comprobamos como el continuismo no solo es algo obligado por un ambiente aristocrático, sino que está presente en un medio plenamente ruralizado ${ }^{87}$.

\subsection{Oviedo. La capital del Reino de los astures Siguiendo El MOdelo del Toledo HISPANOGODO}

Hubo un momento en el que el reino de los astures tenía que recibir un gran tratamiento monumental que representase el imaginario de aquellos planteamientos ideológicos que defendía. El texto que es más explícito a este respecto es muy conocido, y se refiere a la actuación personal de Alfonso II en la corte de Oviedo. Las tres grandes crónicas hacen una pormenorizada relación/descripción de la edilicia religiosa de esta nueva corte, pero, aunque brevemente, tampoco se olvidan de la arquitectura palatina. La Rotensis se refiere a esta arquitectura palatina en los siguientes términos: nam et regia palatia, balnea, promptuaria atque uniuersa stipendia formauit et instruere precepi $i^{88}$. El traductor interpreta así los principales edificios del conjunto palatino: "palacios regios", "baños", "almacenes" y "toda clase de servicios" 89 . Algo más exacta en la nomenclatura funcional es la descripción que de los mismos palacios realiza la Crónica ad Sebastianum: nam et regalia palatia, balnea, triclinia uel domata atque pretoria construxit decora et omnia regni utensilia fabrefecit pulche-

85 F. J. FERNÁNDEZ NIETO, "La pizarra visigoda de Carrio y el horizonte clásico de los chalazophylakez", Antigüedad y Cristianismo, 14 (1997), pp. 259-286.

86 Ibidem.

87 Vid. nota $\mathrm{n}^{\circ} 94$.

88 Rotensis, p. 140.

89 Traducción en J. GIL FERNÁNDEZ, J. L. MORALEJO y J. I. RUÍZ DE LA PEÑA, op. cit., 1985, p. 214. 
rrima $a^{90}$. Como se aprecia, introduce como novedoso "los triclinios", "los solarios", "salas de consejo" sin olvidarse de señalar, todo aquello que era necesario como espacio representativo del reino ${ }^{91}$. Es verdad que muchos de estos elementos son los propios de una villa romana de carácter monumental, pero no creo que se pueda dudar de la intención de los cronistas: pretenden precisar con todo detalle los elementos que constituían un palacio real que de verdad existía. Ni tenemos espacio para entrar en detalle sobre estas formas, ni para nuestra tesis es necesario. Pero sí me gustaría fijarme en un detalle de la Albeldense al referirse a estos palacios: simulque cum regiis palatiis picturis diuersis decoraui ${ }^{92}$. Para estas pinturas que decoraron las dependencias palatinas contamos con una referencia única para el arte de esta época. Todos sabemos que la representación de cortinajes con arquitecturas es uno de los tópicos de la tradición iconográfica áulica de los romanos. Grandes lienzos de los murales de Santullano serían magnificas ilustraciones de lo que debió ser la decoración pictórica de estas dependencia regias de Oviedo (fig. 11). Conviene no olvidar al respecto que el promotor de estas obras fue el mismo, Alfonso II el Grande.

Para terminar este apartado, me gustaría hacer un breve comentario sobre la interpretación que la Albeldense realiza después de enumerar la labor edilicia llevada a cabo por Alfonso II en Oviedo: omnemque Gotorum ordinem, sicuti Toleto fuerat, tam in ecclesia quam palatio in Ouetao cuncta statuit ${ }^{93}$. Intención y significado creo que en principio nadie duda de ella, sin embargo creo que hay ciertos matices importantes que señalar. El reivindicar el Ordo gotorum tiene una intención evidente que creo que ya he dejado claro: legitimar un linaje y los derechos que a este le corresponden. Pero aquí, además de esto, se está reconstruyendo la escenografía representativa en la que vivía la corte de los visigodos en Toledo. Este escenario es la arquitectura y el arte mobiliar tardorromano de aquella época, o por utilizar otro término más vulgarizado es el arte hispanogodo.

2.3.1. La decoración de Santullano. El imaginario de los Religiosos de Élite y SU EXTRAORDINARIA MATERIALIZACIÓN A LA ROMANA

Si el contenido de la pizarra de Carrio nos muestra la viva expresión de un cristianismo impregnado de paganismo, propio de un mundo campesino y popular ${ }^{94}$, la decoración mural de Santullano es todo lo contrario. Representa unas ideas sobre lo

90 Ad Sebastianum, p. 141.

91 No se olvide que el texto referido a estas construcciones va regido por "regni".

92 Albeldense, XV, 9, p. 174.

93 Ibídem.

94 Díaz y Díaz supone que la elaboración de este tipo de obras supone "que se trata de un escrito en letra común, que requiere, por consiguiente, un grado determinado de formación en el que es capaz de utilizar la escritura: desde este punto de vista no nos hallamos ante un nivel cultural ínfimo. También hay que recordar que buena parte del texto hace suponer, como hemos visto, conocimiento de la Pasión de Cristóbal, y de la de Bartolomé, así como de fórmulas que recuerdan la redacción usual en donaciones" (M. C. DÍAZ y DÍAZ, op. cit., 2001, p. 147). Pienso que la pizarra debe ser analizada desde dos planos distintos: el amanuense que hace y vende el amuleto; el que disfruta/utiliza el amuleto. ¿A quién se refiere Díaz y Díaz? Él no hace distinciones, considera que uno y otro es el mismo. Pudiera ser, pero en ese caso deberíamos pensar en un terrateniente con una cierta formación intelectual. En todo caso, y teniendo en cuenta cuál fue el posible origen de la pieza, lo 


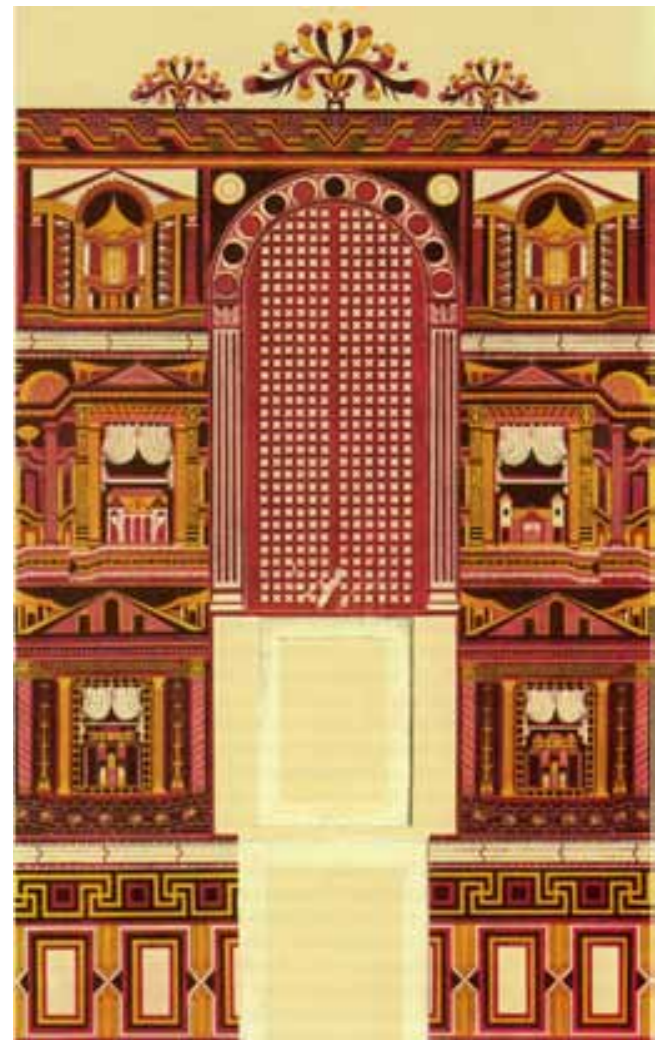

Fig. 11

esencial del mensaje cristiano, de muy difícil comprensión, nada populares y sí adecuadas para unos hombres de iglesia con una formación propia de una elite. Por otro lado, frente a la pobreza ornamental de la pizarra, la letra común y la rudimentaria decoración de pentalfas, Santullano se decora con un imaginario rico y deslumbrador propio de una buena romanidad y materialmente realizado con una técnica de estuco romano que la Edad Media europea no había vuelto, ni volverá a practicar ${ }^{95}$.

No es el lugar aquí de entrar en el detalle del programa iconográfico, pero sí de hacer una referencia de carácter genérico. Se han dado multitud de interpretaciones, pero, desde mi punto de vista, solo una es indiscutible y perfectamente admitida por todos: es un programa anicónico. En los principios del cristianismo la idea de un Dios no representable, continuidad evidente de los fundamentos teológicos judíos, fue cediendo ante la presión de unos fieles que necesitaban ver materializada la forma del dios en que depositaban su fe. Surgieron así dos posturas: $1^{\mathrm{a}}$ ) una concesión al pueblo permitiéndole usar una imagen de Dios de aspecto áulico; $2^{\mathrm{a}}$ ) la parte del

que a mí me interesa resaltar es cómo las prácticas campesinas siguen siendo una continuidad de las de época hispanogoda.

95 Durante los últimos treinta años he venido tratando este tema en numerosos trabajos, vid una síntesis de los mismos en I. G. BANGO TORVISO, op. cit., 2001, pp. 281-290 y 547-559. 


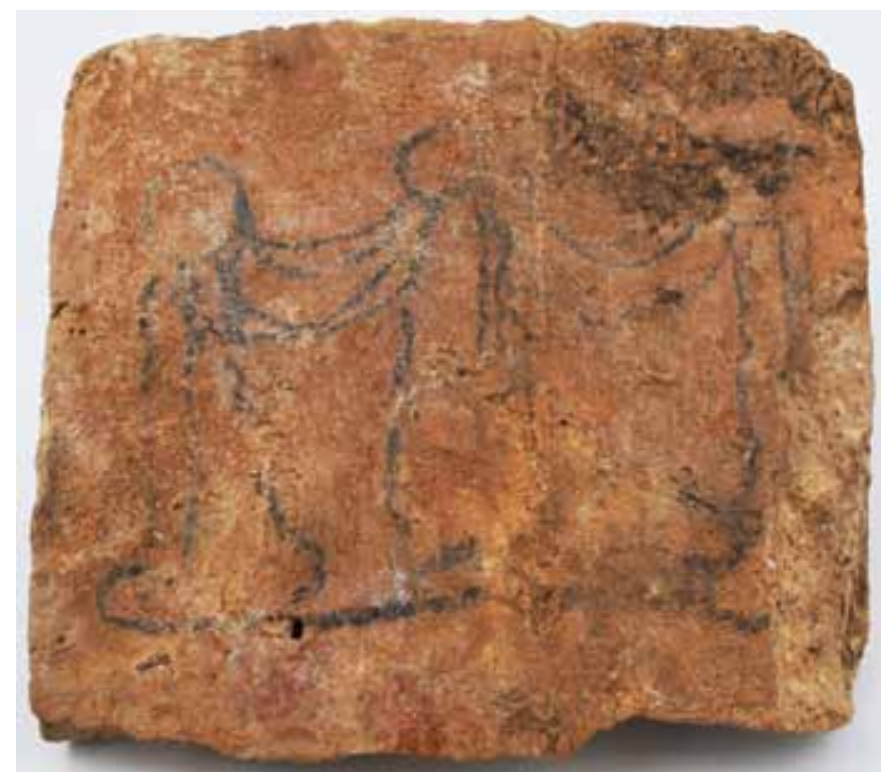

Fig. 12

clero más estricta y minoritaria prefirió mantener su no representación. El concilio de Elvira, con su nec picturas in ecclessia, se hace eco del tema, que será mantenido por los padres de los concilios toledanos refiriéndose a un Deus invisibilis. Algunos hispani importantes en la corte carolingia hicieron manifestación pública de estos planteamientos en la decoración de sus templos y códices. En la misma línea el promotor de Santullano, Alfonso II, en su célebre testamento del 812, también habla de un Deus absconditus o invisibilis. Por esta razón los palacios celestiales, figurados por las arquitecturas no están presididos por una maiestas divina personificada, sino por el símbolo de la cruz que evoca el sacrificio del Hijo, pero en definitiva un Dios irrepresentable.

Los grandes encuadres que cierran sus cortinas o que éstas, a medio abrir, dejan ver lo que hay tras ellas son modelos icónicos muy empleados por la plástica romana. Frente a mi tesis que siempre los he considerado la continuidad de un léxico figurativo tardorromano hispano, se ha llegado a defender una dependencia de modelos carolingios que nada tienen que ver con el significado, la materia o la factura ${ }^{96}$. No se conoce

96 Todavía algunos reticentes buscaban paralelos en la miniatura carolingia, sin duda modelos romanos pero de iconografía muy diferente, y significado iconológico aún más distinto. A este respecto pueden verse la cantidad de publicaciones que muestran "alegremente" la adoración del Cordero de los Evangelios de SaintMédard de Soissons (Paris, B.N., Lat. 8850, fol. $1 \mathrm{v}^{\mathrm{o}}$ ) como referente de las pinturas de San Julián de los Prados. Cosa distinta es lo que defiende Jerrilynn Dodds, quien ve en el programa de Santullano la intención de Alfonso II de combatir el adopcionismo y así la autoridad de la iglesia toledana, aliándose con el planteamiento teológico carolingio (J. DODDS, "Las pinturas de San Julián de los Prados. Arte, diplomacia y herejía", Goya, 191 (1986), pp. 258-263). Es indiscutible que se produjo esta alianza en la polémica adopcionista, pero el concepto anicónico, tanto en Asturias como en la órbita carolingia, responde a la actuación muy concreta de padres formados en la tradición de la iglesia hispanogoda. Por otro lado, tal como veremos a continuación, los modelos icónicos utilizados se encuentran básicamente en la tardorromanidad asturiana. 

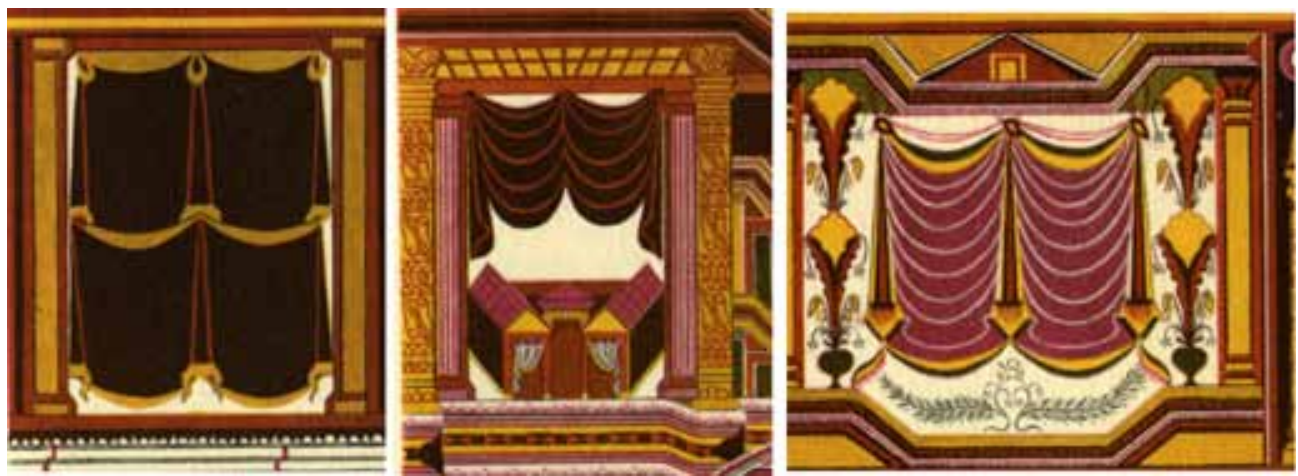

Fig. 13

un estucado de un grosor de un centímetro en la Europa coetánea, los viejos recursos romanos de este tipo hacía mucho tiempo que ya habían desaparecido. Si la universalidad de las formas podría cuestionar un posible origen de las mismas, la existencia de esta técnica en la Asturias del siglo IX solo se puede justificar por la continuidad de su empleo. Pero es que además el imaginario tardorromano de Asturias es suficiente por sí mismo para inspirar las pinturas asturianas. El rico yacimiento de Veranes nos suministra algunos testimonios que explicarían el desarrollo ornamental de los murales de Santullano. Un grafiti sobre un fragmento de ladrillo (fig. 12), seguramente un grosero apunte de boceto, nos aclara el origen de los cortinajes ${ }^{97}$. Presenta un dibujo de trazos esquemáticos, donde se esbozan los pliegues verticales y horizontales de una cortina que se sujeta por medio de tres anillas u ojales. La central más alta, y cuyo extremo inferior parece descansar sobre un pavimento. El esquematismo del dibujo y las características propias de los trazos de carboncillo sobre la superficie irregular del ladrillo no permiten vislumbrar con nitidez la composición, aunque es posible que las cortinas se representen enmarcadas en una arquitectura de dos columnas a la que le faltaría un dintel, arco o frontón ${ }^{98}$. Si comparamos esta imagen con las soluciones de Santullano (fig. 13), veremos que responden a un mismo criterio de representación. Es curioso observar el alzamiento central en los dos cortinajes. Para entender mejor la comparación conviene recordar que en Santullano se trata de un trabajo pictórico terminado, mientras que en el ladrillo, tal como indican sus descubridores, no deja de ser un esbozo de croquis para un proyecto mayor. Pero que estas coincidencias no son un accidente aislado, lo demuestra el espíritu ornamental que rige en las pinturas del reino astur, un geometrismo tardorromano evidente, que también tiene sus paralelos en los mosaicos de Veranes. Dos encontrados en esta villa asturiana son una buena

97 C. FERNÁNDEZ OCHOA, F. GIL SENDINO y J. DEL HOYO, "Una inscripción y un dibujo sobre ladrillo hallados en la villa romana de Veranes (Gijón, Asturias)", Archivo Español de Arqueología, 80 (2007), pp. 183-190.

98 He preferido respetar la descripción de sus descubridores, introduciendo solo la posibilidad de que en vez de anillas fuesen ojales (Ibídem, p. 186). 


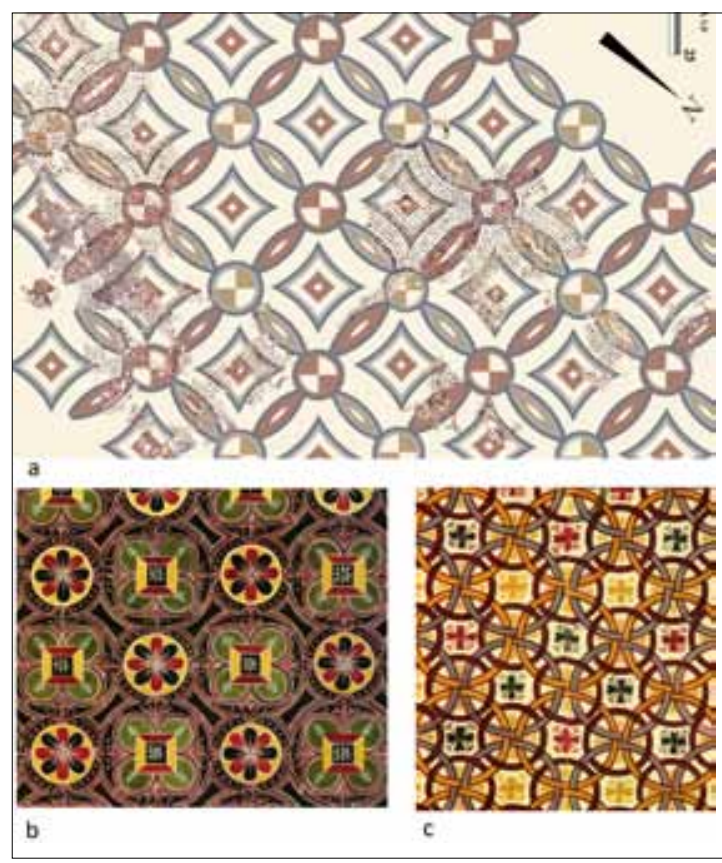

Fig. 14

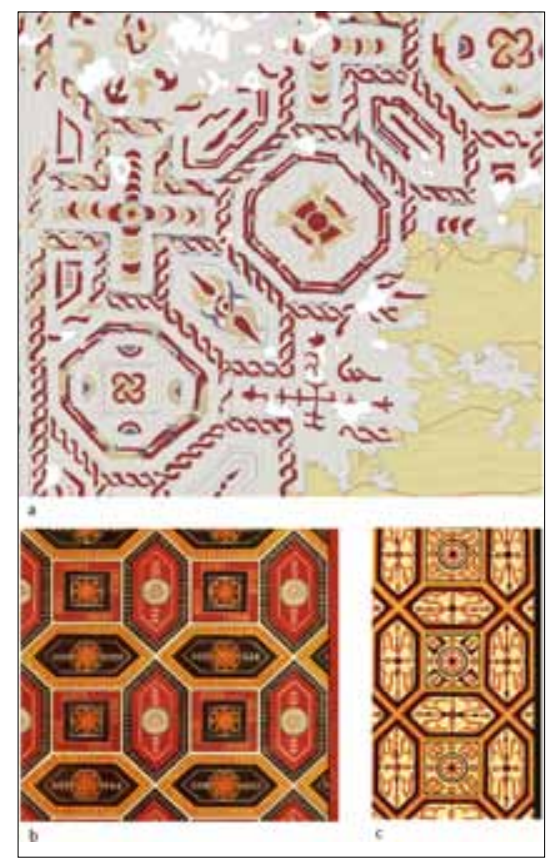

Fig. 15

prueba de ello ${ }^{99}$. El tratamiento de círculos (fig. 14), o el juego de líneas describiendo característicos hexágonos achatados (fig. 15). Incluso puede observarse la comunión formal con la abstracción vegetal que decora el interior de los mismos.

Si se me permite, creo que no sería demasiado especulativo lo siguiente: En la Asturias del siglo IX existe una minoría clerical que desea realizar un programa anicónico en la tradición hispana bien documentada, que cuenta para su materialización con pintores a la romana tanto en los recursos técnicos como en los icónicos.

\subsubsection{El panteón Real de Oviedo. El símbolo de un linaje}

De la labor edilicia de Alfonso II en Oviedo no conservamos el panteón real, pero tenemos un buen conocimiento de él. Es evidente la fuerte carga simbólica que el monarca quiere dar al panteón. Es el lugar donde se enterrarán los monarcas, es decir el linaje legitimador. Sobre él nos dice la Crónica ad Sebastianum "que edificó también una iglesia en honor de Santa María siempre Virgen, hacia la parte Norte, pegada a la iglesia ya dicha... además en la parte occidental de este venerable edificio, construyó un recinto para sepultar los cuerpos de los reyes" ${ }^{100}$. Al tratar de su muerte nos vuelve a hablar de este lugar: "Más su cuerpo, sepultado con unas exequias llenas de

99 V. ARRIBAS et alii, "Métodos topocartográficos para la documentación de mosaicos in situ. Aplicaciones en la villa tardorromana de Veranes", Arqueología de la Arquitectura, 2 (2003), pp. 123-130.

100 Ad Sebastianum, 21, p. 215. 


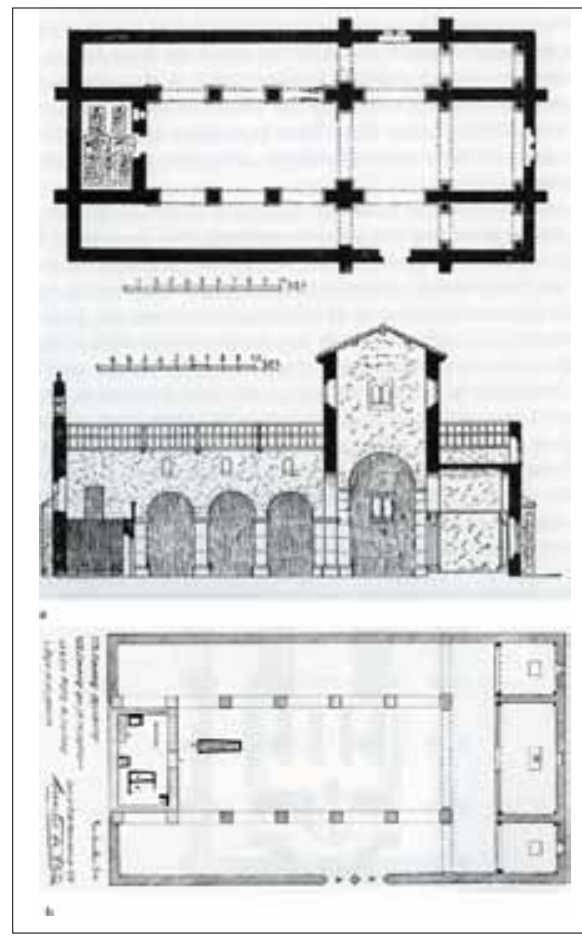

Fig. 16

veneración en la ya nombrada iglesia de Santa María, por él fundada, en un túmulo de piedra, descansa en paz"101.

De su forma, viejas descripciones y planos nos permiten tener una idea bastante aproximada. El plano de Selgas (1908) ${ }^{102}$ y el de Llano $(1926)^{103}$, con ciertas diferencias que para lo que aquí nos interesa ahora no tienen mayor trascendencia, nos permiten tener una imagen plástica de lo que se nos ha trasmitido en descripciones literarias (fig. 16). Se trata de un espacio cerrado dispuesto como contraábside en la parte occidental de la nave central. No se puede afirmar que se siguiese aquí la forma de panteón regio de los monarcas visigodos, pues lo que conocemos de sus enterramientos no pasa de lo meramente legendario ${ }^{104}$. Hace más de treinta años que sosten-

101 Ibidem,

102 F. SELGAS, Monumentos ovetenses del siglo IX, Gijón, 1991, p. 73. Esta obra contiene una serie de artículos del autor publicados en el Boletín de la Sociedad Española de Excursiones del año 1908.

103 A. LLANO ROZA DE AMPUDIA, "Descubrimientos arqueológicos. La iglesia de Santa María del Rey Casto, siglo IX”, Revista Covadonga, 1926, pp. 834-837.

104 Sobre la problemática de los enterramientos de los reyes visigodos ha tratado recientemente $\mathrm{R}$. ALONSO ("Hornija, Bamba, Pampliega: las elecciones funerarias de los reyes hispanovisigodos", Territorio, Sociedad y Poder, 3 (2008), pp. 13-27). Ignoro cómo ha podido cometer el error de afirmar que doy por buena la información de la Continuatio (p.16, n. 13), cuando, al referirme a la información de estos enterramientos, afirmo que es falsa (I. G. BANGO TORVISO, op. cit., 2001, p. 353). Hubiera sido más interesante que Alonso, en sus trabajos, hubiera recogido la interpretación que sobre el panteón asturiano en relación con un posible modelo de época hispanogoda sintetizo aquí en función de mis estudios anteriores. 
go que esta forma de enterramiento responde a una solución de espacios funerarios para privilegiados que se conocían perfectamente en época hispanogoda. Algunas iglesias contraábsidadas hispanas, de origen africano, muestran su segundo ábside con un cimiento corrido que evidencia un espacio cerrado con un muro pleno, cuyos vanos, que muy seguramente los tuvo, no somos capaces de reconstruir, ni siquiera de manera ideal ${ }^{105}$. Sin duda algunos de estos ábsides pudieron servir de habitationes sepulchri, donde se enterraban personajes ilustres como en algún caso se citan prelados en las fuentes literarias. Esta solución de panteón privilegiado dispuesto de forma contraábsidada es la referencia para el cementerio real de Oviedo que a su vez tendrá su continuidad tipológica en el cementerio real leonés (San Juan y San Pelayo/San Isidoro de León) y, bajo una forma distinta de contraábside, en Santiago de Peñalba.

La construcción del panteón ovetense por parte de Alfonso II tenía la intención de perpetuar la memoria del linaje real, era una obra más de la política de gestos del monarca por ensalzar y consolidar la institución regia. Dado el nulo conocimiento que tenemos de los enterramientos reales visigodos, no podemos afirmar que la disposición del panteón asturiano siguiese un posible modelo regio visigodo, pero sin duda se recurre a una forma tipológica de enterramiento privilegiado muy conocida por la arquitectura hispanogoda.

\section{A MODO DE CONCLUSIÓN}

En el momento que se produce la invasión musulmana, la vieja Hispania gobernada por los visigodos seguía manteniendo una cultura tardorromana, aunque empobrecida por la crisis que caracterizó los últimos reinados de la monarquía de Toledo. En principio, la cultura material tardorromana hispana no fue modificada por los invasores. Testimonio de ello es el edificio más monumental y significativo de la nueva realidad política, la mezquita de Córdoba en su primera fase constructiva. En el reino emergente astur, la tardorromanidad existente más las aportaciones de los emigrados sureños será suficiente para seguir manteniendo una cultura a la antigua. Por esta razón, la calificación estilística de estas creaciones artísticas conviene mejor con el pasado que subsiste que con el futuro. No estamos en absoluto con el prerrománico, una experimentación que conducirá a la aparición del románico, sino, tal como ya he comentado en diversas ocasiones, con el "canto del cisne del arte tardorromano".

En paralelo con la realidad material, se produce una voluntad política de reafirmarse en el ideario del pasado como un factor determinante de legitimación, con lo que esto supuso de emulación de determinadas formas emblemáticas del pasado. Este fenómeno ha sido denominado visigotización, concepto, que con el paso del tiempo, adquirirá ciertas connotaciones políticas que contribuirán a una visión sesgada y anacrónica del mismo. Incluso se ha llegado a negar algo tan evidente como que el principal impulsor del mismo fue Alfonso II.

105 Ibídem, p. 89, fig. 54. 